\title{
COLUSIÓN Y RESPONSABILIDAD CIVIL POR DAÑO COLECTIVO A LOS CONSUMIDORES
}

\section{CARTEL AND CIVIL LIABILITY FOR COLLECTIVE DAMAGE TO CONSUMERS}

Gabriel Hernández Paulsen*

\section{RESUMEN}

Se abordan los problemas centrales de la responsabilidad civil por los perjuicios colectivos o difusos provocados por la colusión a los consumidores. Específicamente, la legitimación de los consumidores (exigencia de "vínculo contractual" e incidencia de la sentencia de libre competencia), la culpabilidad y el daño (naturaleza, cuantificación y causalidad).

Palabras clave: Colusión, responsabilidad civil, daño colectivo, consumidores.

\section{AbStRact}

It addresses the central issues of liability for collective or diffuse damages caused by cartel to consumers. Specifically, standing of consumers (requirement of "contractual link" and incidence of the free competition judgment), culpability and damage (nature, quantification and causality).

Key words: Cartel, civil liability, collective damage, consumers.

* Director y profesor del Departamento de Derecho Privado de la Facultad de Derecho de la Universidad de Chile. Doctor en Derecho Privado por la Universidad Autónoma de Barcelona. Dirección postal: Pío Nono 1, Providencia, Santiago. Correo electrónico: ghernan@derecho.uchile.cl. Artículo recibido el 16 de mayo de 2017 y aceptado para su publicación el 13 de marzo de 2018. 


\section{RELACIONES ENTRE LOS DERECHOS \\ DE LA COMPETENCIA Y DEL CONSUMO}

Los casos de concertación empresarial para alzar precios conocidos en los últimos años son los primeros en Chile en que se ha discutido sobre la responsabilidad civil por los daños causados a los consumidores por un ilícito anticompetitivo (antitrust injury), en específico, el de colusión, quizá la más importante infracción al derecho de la competencia ${ }^{1}$.

Según el art. 3 (1) del DL 211, el ilícito contra el mercado consiste en "cualquier hecho, acto o convención que impida, restrinja o entorpezca la libre competencia, o que tienda a producir dichos efectos" 2 .

En cuanto a la colusión, el literal a) del precepto considera ilícitos contra el mercado

"los acuerdos o prácticas concertadas que involucren a competidores entre sí, y que consistan en fijar precios de venta o de compra, limitar la producción, asignarse zonas o cuotas de mercado o afectar el resultado de procesos de licitación, así como los acuerdos o prácticas concertadas que, confiriéndoles poder de mercado a los competidores, consistan en determinar condiciones de comercialización o excluir a actuales o potenciales competidores"3.

Para la Corte Suprema, los elementos de la colusión son el acuerdo entre agentes económicos en una conducta anticompetitiva, realizado con el fin de obtener beneficios para los concertados o perjudicar a terceros, sin que deban haber ignorado el potencial de dicha conducta para afectar la libre competencia ${ }^{4}$.

Antes de adentrarme en el detalle del tópico que abordo, conviene tener a la vista los antecedentes de los casos conocidos en el último tiempo en Chile.

${ }^{1}$ Eyzaguirre y Grunberg (2008), p. 57; Tapia (2010), p. 115.

${ }^{2}$ VALDÉs (2009), p. 241 y ss.

${ }^{3}$ Conforme a la sentencia de la Corte Suprema pronunciada en Requerimiento de la FNE contra Farmacias Ahumada S.A. y otros (2012), "una de las infracciones a las reglas de la libre competencia es la colusión horizontal, la cual muestra un fuerte incentivo a producir menos y cobrar más caro. Se evita con ello la mutua competencia. Es una forma de monopolio. Se ha dicho que el cartel es una organización creada por algunos productores para la venta en común de su producto, lo que constituye una restricción seria de la competencia, en especial cuando dichos agentes tienen preponderancia en el mercado. Es un acuerdo en busca de beneficios recíprocos en perjuicio de los consumidores" (c. sexagésimo séptimo). Véase también la sentencia de la misma Corte en Requerimiento de la FNE contra Agrícola Agrosuper S.A. y otros (2015) (c. trigésimo sexto).

${ }^{4}$ Requerimiento de la FNE contra Farmacias Ahumada S.A. y otros (2012) (c. septuagésimo octavo). Eyzaguirre y Grunberg (2008), pp. 59-65. 


\section{Caso farmacias}

El 31 de enero de 2012, el TDLC condenó a dos empresas farmacéuticas a pagar una multa por coludirse (con otra) para subir el precio de medicamentos para patologías crónicas (esquizofrenia, trastornos bipolares, osteoporosis, Alzheimer, depresión, asma, hipertensión, insuficiencia cardiaca, etc.). La Corte Suprema, el 7 de septiembre de 2012, confirmó la condena ${ }^{5}$. El SERNAC demandó colectivamente a las condenadas indemnización para los consumidores ${ }^{6}$.

\section{Caso pollos}

El 25 de septiembre de 2014, el TDLC condenó a tres empresas avícolas por concertarse para alzar el precio de la carne de pollo. La sentencia fue ratificada por la Corte Suprema el 29 de octubre de 2015․ El SERNAC demandó indemnización colectiva a favor de los consumidores ${ }^{8}$.

\section{Caso papel}

En este caso, el SERNAC demandó responsabilidad civil a una empresa por convenir con otra incrementar el precio de sus productos (papel higiénico, servilletas, toallas y pañuelos $)^{9}$. El motivo fue que la demandada se negó a participar en la mediación con la otra empresa coludida. La acción se interpuso en paralelo al juicio seguido ante el TDLC ${ }^{10}$. El SERNAC y dos asociaciones de consumidores celebraron una conciliación con la empresa que no fue demandada, acordando una compensación para aquellos.

${ }^{5}$ Requerimiento de la FNE contra Farmacias Ahumada S.A. y Otros (2012).

${ }^{6}$ Servicio Nacional del Consumidor con Farmacias Cruz Verde S.A. y otros (2013). La tercera empresa celebró una conciliación con la FNE, ratificada por el TDLC. La conciliación se fundó en la propuesta de un plan de compensación ofrecido por la empresa, que incumplió, provocando la presentación de una demanda en su contra por el SERNAC. El tribunal de primera instancia rechazó la acción. La Corte de Apelaciones de Santiago revocó parcialmente la sentencia y condenó a la empresa -en aplicación de la ley No 19.496 , de 1997- a pagar una multa y a la consignación en la cuenta del tribunal de una suma de dinero como compensación a los afectados. La Corte Suprema anuló el fallo aduciendo que dicha ley no es aplicable al plan de compensación, Corte Suprema, rol No 1540-15, de 7 de marzo de 2016. Véase TAPIA (2017), pp. 78-80.

${ }^{7}$ Requerimiento de la FNE contra Agrícola Agrosuper S.A. y otros (2015).

${ }^{8}$ Servicio Nacional del Consumidor con Agrícola Agrosuper S.A. y otros (2015).

${ }^{9}$ Servicio Nacional del Consumidor con SCA Chile S.A. (2016).

${ }^{10}$ Requerimiento de la FNE contra CMPC Tissue S.A. y Otra (2015). 


\section{Caso supermercados}

Adicionalmente, está en curso ante el TDLC un juicio contra tres supermercados por alzas concertadas de los precios de la carne de pollo ${ }^{11}$.

\section{Caso pañales}

También habría operado colusión en el mercado de los pañales. No obstante, en un comunicado de 30 de diciembre de 2016, la FNE señaló que cerraba la investigación por considerar prescrita la acción para perseguir a las empresas concertadas ${ }^{12}$.

Los casos reseñados ponen de relieve la relación de los derechos de la competencia y del consumo, que aspiran a proteger el adecuado funcionamiento del mercado y a los consumidores ${ }^{13}$.

En dicho sentido, el TDLC ha señalado:

"la colusión constituye, unánimemente en la doctrina, en nuestra legislación y en la jurisprudencia de este Tribunal como de la Excma. Corte Suprema, el más lesivo de los atentados a la libre competencia, toda vez que supone suprimir de raíz la incertidumbre y la libre iniciativa propia de los procesos competitivos, reemplazándola por una conspiración entre competidores en perjuicio del bienestar social y los consumidores" ${ }^{14}$.

Lo propio hizo la Corte Suprema al dictaminar:

"la política económica de libre mercado tiene como presupuesto fundamental la competencia entre los agentes económicos, en busca de hacer más beneficioso el mercado a favor de los consumidores, teniendo presente que deben operar con toda autonomía las leyes de la oferta y la demanda, puesto que incidirán directamente respecto de la calidad de los productos y se potenciará la eficiencia, (2016).

${ }^{11}$ Requerimiento de la Fiscalía Nacional Económica contra Cencosud S.A. y Otras

${ }^{12}$ www.fne.gob.cl/2016/12/30/fne-cierra-investigacion-sobre-mercado-de-los-panalespor-prescripcion/ [fecha de consulta: 1 de marzo de 2018].

${ }^{13}$ Berenguer (2011), p. 51; Miranda (1999), pp. 48-54; Martínez de Aguirre (1994), pp. 46-47; SAlelles (2009), pp. 172 y 175. Una opinión discrepante en VALDÉs (2009), pp. 149-151.

${ }^{14}$ Requerimiento de la FNE contra Farmacias Ahumada S.A. y otros (2012) (c. centesimo nonagésimo quinto). También, requerimiento de la FNE contra Agrícola Agrosuper S.A. y otros (2015) (c. tricentésimo cuadragésimo octavo). 
eficacia, efectividad e innovación de los procesos productivos, como la intermediación de los bienes y servicios, reportando mayor satisfacción de los consumidores considerando el costo-beneficio, todo sobre la base de una sana y libre competencia en un mercado robusto"15.

En la actualidad, es habitual que los ordenamientos jurídicos concedan a los privados y, en específico, a los consumidores, derechos directos para prevenir, pesquisar y reprimir las infracciones al derecho de la competencia, como la colusión. Así, es frecuente que les otorguen el derecho a denunciar los ilícitos contra el mercado al efecto de aplicar sanciones a los infractores ${ }^{16}$, pedir medidas precautorias, impetrar la nulidad de los acuerdos en que se plasmen y solicitar indemnización ${ }^{17}$.

Los mencionados derechos se insertan en la llamada aplicación privada del derecho de la competencia (private enforcement) que, con la pública (public enforcement $)^{18}$, colabora en la detección, disuasión y castigo de los ilícitos contra la competencia, como la colusión ${ }^{19}$.

Según veremos, mientras en Estados Unidos existe una sólida tradición de aplicación del private enforcement, en la Unión Europea su utilización ha sido menos intensa, si bien en virtud de recientes cambios normativos se espera que aumente ${ }^{20}$.

Conforme a lo apuntado, una alternativa a disposición de los consumidores para contribuir al cumplimiento del derecho de la competencia es la deducción de acciones para obtener el resarcimiento de los daños causados por la colusión ${ }^{21}$. A este efecto, pueden interponer una acción

${ }^{15}$ Requerimiento de la FNE contra Farmacias Ahumada S.A. y otros (2012) (c. septuagésimo séptimo). Asimismo, c. sexagésimo séptimo del fallo y sentencia de la misma corte en Requerimiento de la FNE contra Agrícola Agrosuper S.A. y otros (2015) (c. trigésimo séptimo). Y también Fuch y Vives (2015), p. 963.

${ }^{16} \mathrm{El}$ art. 20 (2) del DL 211 establece que el procedimiento ante el TDLC "podrá iniciarse por requerimiento del Fiscal Nacional Económico o por demanda de algún particular".

${ }^{17}$ Berenguer (2011), p. 51.

${ }^{18}$ Respecto de ambas, Migani (2014), p. 82 y ss.; Komninos (2008), p. 7 y ss.; IoAnniDOU (2015), p. 12 y ss.

${ }^{19}$ Lande (2011), pp. 73-74; Cavanagh (2010), pp. 631-636; Berenguer (2011), pp. 5960; Hamilton y Henry (2012), pp. 111-112; Banfi (2013), p. 223; Carpagnano (2007), pp. 10-11. Naturalmente, la preferencia o primacía de cada una depende del ilícito cometido. VAN DER BERGH (2013), p. 15 y ss.

${ }^{20}$ Geradin (2015), p. 1079; Beaton-Wells (2016), pp. 685-689.

${ }^{21}$ Es ilustrativa la sentencia del Tribunal de Justicia de la Unión Europea pronunciada en Courage Ltd. v. Crehan (2001), cuyo c. 27, respecto del derecho a demandar indemnización ante ilícitos contra la competencia, señala lo siguiente: "en efecto, un derecho de esta índole refuerza la operatividad de las normas comunitarias de competencia y 
individual o una colectiva. Este trabajo se refiere a la segunda, principalmente, a la luz del Derecho nacional.

\section{Aproximación a la legitimación de los CONSUmidores PARA DEMANDAR COLECTIVAMENTE INDEMNIZACIÓN DE LOS DAÑOS CAUSADOS POR LA COLUSIÓN}

\section{Preliminar}

El detrimento provocado en concreto a los consumidores a causa de la colusión es diferente del menoscabo al mercado o antitrust en sí, representado, en el ámbito social, por la merma de las transacciones o de la eficiencia económica (deadweight welfare loss) ${ }^{22}$. Asimismo, es distinto del producido por el típico incumplimiento del contrato de consumo o por un "accidente" de consumo ${ }^{23}$.

Los perjuicios ocasionados a los consumidores por la colusión están representados por los que padecen producto de la infracción al derecho de la competencia, siendo el más destacado el sobreprecio pagado (overcharge), consistente en la diferencia entre el precio de mercado y el colusivo ${ }^{24}$.

En relación con dichos perjuicios, pueden detectarse, en resumen, dos tipos de supuestos. Primero, aquellos en que los consumidores han contratado con las empresas coludidas, en que el daño que sufren está representado principalmente por el sobreprecio pagado ("Caso farmacias"). Segundo, aquellos en que los consumidores no contrataron con dichas empresas, sino con otra, en que, básicamente, el detrimento padecido es el sobreprecio pagado a su proveedor, cuando este les cargó todo o parte del sobrecosto que a su vez pagó a una de las empresas concertadas ("Caso pollos") ${ }^{25}$.

En virtud de lo señalado, la primera interrogante que se ha planteado en este ámbito es si, aparte de ostentar legitimación para demandar indemnización los rivales del infractor y sus compradores directos, la tienen

puede disuadir los acuerdos o prácticas, a menudo encubiertos, que puedan restringir o falsear el juego de la competencia. Desde este punto de vista, las acciones que reclaman indemnizaciones por daños y perjuicios ante los órganos jurisdiccionales nacionales pueden contribuir sustancialmente al mantenimiento de una competencia efectiva en la Comunidad".

${ }^{22}$ Eyzaguirre y Grunberg (2008), p. 59; Banfi (2013), pp. 224-225; Lewin (2011), p. 46.

${ }^{23}$ Contardo (2013), p. 124.

${ }^{24}$ Cavanagh (2010), p. 632; Lewin (2011), pp. 46-48. Sobre los presupuestos de la responsabilidad civil por ilícito anticompetitivo, BuCAN (2014), p. 62 y ss.; Komninos (2008), p. 190 y ss.

${ }^{25}$ Cengiz (2010), p. 43. 
los compradores indirectos y los consumidores, sobre todo para deducir una acción colectiva ${ }^{26}$.

En el anterior sentido, cabe tener en cuenta que el art. 30 del DL 211 establece el derecho a resarcimiento para los perjudicados por un ilícito contra el mercado y, asimismo, que el art. 51 de la LPDC otorga legitimación para deducir acciones colectivas al SERNAC, las asociaciones de consumidores y a grupos de estos de mínimo cincuenta personas ${ }^{27}$.

Antes de la reforma efectuada a los arts. 30 del DL 211 y 51 de la LPDC por la ley $\mathrm{N}^{\circ} 20.945$, de 30 de agosto de 2016 (ley No 20.945), se discutió arduamente en los juicios de responsabilidad civil por los daños causados a los consumidores por la colusión acerca de si estaban habilitados para deducir una acción colectiva al efecto de ser indemnizados. Tras la referida modificación, ha quedado claro que la tienen ${ }^{28}$.

\section{Antecedentes comparados}

En Estados Unidos, la posibilidad de deducir una acción indemnizatoria por los detrimentos causados por un ilícito antitrust surge de la sección 7 de la Sherman Act (1890) y de la sección 4 de la Clayton Act $(1914)^{29}$.

La jurisprudencia federal de dicho país ha circunscrito la legitimación para demandar indemnización por los daños provenientes de un ilícito contra el mercado a los rivales y compradores directos, no reconociéndosela a los compradores indirectos ni a los consumidores ${ }^{30}$. Casos paradigmáticos son Hanover Shoe Inc. v. United Shoe Machinery Corp (1968) e Illinois Brick v. Illinois (1977). Por su parte, alguna legislación estatal concede legitimación a los compradores indirectos, habiéndose amparado esta solución por la Corte Suprema en California v. ARC America Corp

${ }^{26}$ Hamilton y Henry (2012), pp. 111 y 113; Berenguer (2011), p. 59; Van Der Bergh (2013), p. 18 y ss.; LewIN (2011), p. 43. Acerca de los argumentos para negar y otorgar la acción a los compradores indirectos, BANFI (2013), pp. 237-238.

${ }^{27}$ Aguirrezábal (2013a), pp. 1023-1024.

${ }^{28}$ Por ejemplo, en Servicio Nacional del Consumidor con Farmacias Cruz Verde S.A. y otros (2013), la Corte de Apelaciones de Santiago, revocando una resolución del tribunal de primera instancia (rol No 3908-2013, de 2 de diciembre de 2013), consideró admisible la demanda colectiva indemnizatoria deducida por el SERNAC contra las empresas coludidas. Cabe precisar que la etapa de admisibilidad en los juicios colectivos regidos por la LPDC busca evitar la interposición de acciones "frívolas" o la proliferación de una "industria del juicio colectivo" a través de un examen formal de la demanda. No obstante, en los hechos, el mero control formal se ha transformado en uno de fondo que, incluso, da lugar a complejos debates probatorios, lo que trae como consecuencia una acusada dilación de los procesos. Ossa y Álvarez (2013), pp. 267-268.

${ }^{29}$ Hamilton y Henry (2012), p. 114; Cengiz (2010), pp. 45-46.

${ }^{30}$ Lewin (2011), pp. 48-49; Cengiz (2010), p. 46; Hamilton y Henry (2012), p. 113. 
$(1989)^{31}$. En la misma línea, la Antitrust Modernization Commission propuso, en 2007, recepcionar dicha solución en el ámbito federal ${ }^{32}$.

La Unión Europea, sobre todo a partir del Libro Blanco. Acciones de danos y perjuicios por incumplimiento de las normas comunitarias de defensa de la competencia $^{33}$, reconoce legitimación activa a todos los perjudicados por un ilícito antitrus $t^{34}$. Como consecuencia, la directiva 2014/104/UE ${ }^{35}$ permitió demandar resarcimiento a los competidores y compradores directos, así como a los consumidores ${ }^{36}$. Su considerando 13 establece lo siguiente:

"el derecho a resarcimiento está reconocido para cualquier persona física o jurídica (consumidores, empresas y administraciones públicas)".

Por su parte, los arts. 3.1 y 12.1 prescriben, respectivamente:

"los Estados miembros velarán por que cualquier persona física o jurídica que haya sufrido un perjuicio ocasionado por una infracción del Derecho de la competencia pueda reclamar y obtener pleno resarcimiento de dicho perjuicio"

"para garantizar la plena efectividad del derecho al resarcimiento pleno establecido en el artículo 3, los Estados miembros velarán por que, con arreglo a las disposiciones previstas en el presente capítulo, el resarcimiento de daños y perjuicios pueda reclamarlo del infractor cualquiera que los haya sufrido, con independencia de que se trate de un comprador directo o indirecto".

${ }^{31}$ Fuch y Vives (2015), pp. 975-979; Van der Bergh (2013), p. 16; Cengiz (2010), p. 48; Lewin (2011), p. 49; Hamilton y Henry (2012), p. 115.

${ }^{32}$ Sobre el private enforcement en Estados Unidos, CAVAnagh (2010), pp. 630-636; Jones y Sufrin (2016), p. 1044 y ss.; Hamilton y Henry (2012), pp. 114-116.

${ }^{33}$ Comisión Europea (2008).

${ }^{34}$ Geradin (2015), pp. 1081-1082; Dunne (2015), p. 582; Cengiz (2010), pp. 40 y 51 ss.; Lewin (2011), p. 49; Hamilton y Henry (2012), pp. 113 y 116-117; Gómez (2011-2012), pp. 96-97. En el ámbito estatal, el caso fundacional en Europa es el inglés Garden Cottage Foods Ltd. v. Milk Marketing Board (1984).

35 "Directiva 2014/104/UE del Parlamento Europeo y del Consejo de 26 de noviembre de 2014 relativa a determinadas normas por las que se rigen las acciones por daños en virtud del Derecho nacional, por infracciones del Derecho de la competencia de los Estados miembros y de la Unión Europea", Diario Oficial de la Unión Europea, sine loco, de 5 de diciembre de 2014, L 349/1.

${ }^{36}$ BÜYÜKSagis (2015), p. 22; Dunne (2015), pp. 581-597. 
La solución de la mencionada directiva es afín con las decisiones adoptadas por el Tribunal de Justicia de la Unión Europea, que ha concluido que, pese a no existir norma expresa, todo perjudicado por un ilícito contra el mercado tiene derecho a indemnización ${ }^{37}$.

Entre los casos fallados por dicho tribunal, el fundacional es Courage Ltd. v. Crehan (2001), en cuya sentencia se lee lo siguiente:

"la plena eficacia del artículo 85 del Tratado y, en particular, el efecto útil de la prohibición establecida en su apartado 1 se verían en entredicho si no existiera la posibilidad de que cualquier persona solicite la reparación del perjuicio que le haya irrogado un contrato o un comportamiento susceptible de restringir o de falsear el juego de la competencia"38.

También constituye un precedente relevante Manfredi y Lloyd v. Adriatico Assicurazioni SpA (2006), en cuyo fallo se repite lo resuelto en Courage ${ }^{39}$.

A lo anterior cabe agregar que -según el Informe Ashurst- en la mayoría de los Estados de la Unión Europea sería posible dar cabida a una amplia legitimación para demandar indemnización por los daños causados por un ilícito contra el mercado ${ }^{40}$.

Ahora bien, respecto de la acción colectiva indemnizatoria que los consumidores pueden deducir para hacer operativo en el ámbito privado el derecho de la competencia, existen dos grandes modelos. El primero es el de las acciones $o p$-in o de inclusión, que requiere, para que los consumidores perjudicados queden ligados por la sentencia del juicio resarcitorio, que manifiesten su expresa voluntad de ser incluidos en la acción colectiva deducida. El otro modelo, llamado op-out o de exclusión, implica asumir que todos los consumidores perjudicados son parte del juicio colectivo, pese a no haber expresado su opción en este sentido, pudiendo excluirse si manifiestan su voluntad de abandonar el colectivo ${ }^{41}$.

${ }^{37}$ Fernández y Moreno-Tapia (2002), p. 9; Geradin (2015), p. 1081. Sobre el private enforcement en el Derecho europeo, Alison y Sufrin (2016), p. 1049 y ss.; Bucan (2014), p. 29 y ss.; Dunne (2015), p. 582.

${ }^{38}$ Apartado 26.

${ }^{39}$ Apartado 60. Respecto de estos casos, Hamilton y Henry (2012), p. 116; Fernández y Moreno-Tapia (2002), pp. 1-11; Carpagnano (2007), pp. 1-21; Komninos (2008), p. 162 y ss.; Cengiz (2010), p. 51y ss.

${ }^{40}$ Waelbroeck, Slater y Even-Shoshan (2004), pp. 6 y 111.

${ }^{41}$ LESKINEN (2011), pp. 285-286; BÜYÜKSAGIS (2015), pp. 26-27. Respecto de los sistemas adoptados por distintos ordenamientos en materia de acciones colectivas en este ámbito, Gómez (2011-2012), p. 97 y ss. Y, también, "Recomendación de la Comisión de 11 de junio de 2013 sobre los principios comunes aplicables a los mecanismos de recurso colectivo de cesación o de indemnización en los Estados miembros en caso de violación de los de- 


\section{El Derecho chileno}

Hasta hace poco y no obstante que el ordenamiento nacional permite solicitar indemnización a todos los afectados por la colusión, sean competidores o consumidores, los casos sobre responsabilidad civil por ilícito anticompetitivo habían estado referidos a los detrimentos causados a los primeros.

Un caso fundacional entre rivales -tras la condena de la Comisión Resolutiva- es Pivcevic y otros con LAN Chile (2006), en que se esgrimieron para sustentar la responsabilidad civil el art. 2314 y siguientes del Código Civil. En la etapa del TDLC, casos importantes son: Sound Colour con United International Pictures Chile (2009), Cementa S.A. con James Hardie Fibrocementos Ltda. (2009), Producción Química y Electrónica Quimel S.A. con James Hardie Fibrocementos Ltda. (2009) y Philip Morris Chile Comercializadora Limitada con Compañía Chilena de Tabacos $(2013)^{42}$.

Por lo que respecta a las acciones indemnizatorias deducidas por consumidores ante los perjuicios provocados por la colusión, cabe tener en cuenta que el art. 30 del DL 211 otorga legitimación para demandar indemnización a cualquier perjudicado por un ilícito contra el mercado.

96 Así, permite a los rivales, los compradores directos y los compradores indirectos, incluidos los consumidores, la deducción de la acción resarcitoria, por ejemplo, ante la colusión ${ }^{43}$.

rechos reconocidos por el Derecho de la Unión" (2013/396/UE), Diario Oficial de la Unión Europea de 27 de julio de 2013, L 201/60. A su respecto, GERAdin (2015), pp. 1086-1095.

${ }_{42}$ Analizados en Banfi (2014), pp. 48-52.

${ }^{43}$ En general, cabe tener en cuenta que el art. 3 e) de la LPDC consagra el derecho básico de los consumidores "a la reparación e indemnización adecuada y oportuna de todos los daños materiales y morales en caso de incumplimiento de cualquiera de las obligaciones contraídas por el proveedor". ContaRdo (2013), pp. 117-132. Adicionalmente, el art. 50 (2) otorga acción indemnizatoria ante "el incumplimiento de las normas contenidas" en la LPDC. CORTEZ (2013), pp. 951-966. Luego, el art. 51 faculta al SERNAC, las asociaciones de consumidores y a grupos de estos para interponer una acción protectora del interés colectivo o difuso, por ejemplo, una indemnizatoria. AguirRezábal (2013a), pp. 1013-1026. En el ámbito internacional, el derecho a la compensación de los consumidores se recoge en las "Directrices de las Naciones Unidas para la protección del consumidor" (2016), V. F.37, que establecen: "los Estados Miembros deben establecer o mantener medidas legales o administrativas para permitir que los consumidores o, en su caso, las organizaciones competentes obtengan compensación mediante procedimientos oficiales o extraoficiales que sean rápidos, justos, transparentes, poco costosos y accesibles". Vinculando los arts. 3 e) y 50 (2) de la LPDC con el ilícito de colusión, cabe apuntar que esta constituye un incumplimiento de las obligaciones del proveedor y de las normas de la LPDC. Esto se debe a que el art. 3, en sus letras a) y b), consagra, respectivamente, los derechos básicos de los consumidores a "la libre elección del bien y servicio" y "a una información veraz y oportuna sobre los bienes y servicios ofrecidos, su 
El citado precepto, por lo que atañe a las acciones individuales, es una aplicación concreta de las reglas generales del Código Civil, a la luz de las cuales cualquier consumidor podría demandar aisladamente resarcimiento por los detrimentos sufridos a consecuencia de la colusión ${ }^{44}$.

En cuanto a las acciones colectivas, cabe tener en cuenta que antes de la entrada en vigencia de la ley $\mathrm{N}^{\mathrm{o}} 20.945$, en los pleitos sobre colusión se discutió acerca de la posibilidad de que los consumidores pudieran deducirlas al efecto de obtener indemnización de los perjuicios que hubieran padecido a consecuencia de aquella. El debate se suscitó porque el art. 30 del DL 211 -luego de la ley No 19.911, de 2003- admitió que cualquier sujeto interpusiera una acción resarcitoria ante el tribunal civil competente, en un procedimiento sumario, sin hacer referencia expresa a la alternativa de deducir una acción colectiva ${ }^{45}$.

De manera que, antes de la ley $\mathrm{N}^{\mathrm{o}} 20.945$, era indiscutible -en aplicación del art. 30 del DL 211- que los consumidores tenían legitimación para incoar una acción individual en el procedimiento sumario. Y, también -en aplicación de las reglas generales-, para hacerlo grupalmente en un procedimiento ordinario, en virtud de los arts. 18, 19 y 21 del Código de Procedimiento Civil, referidos al litis consorcio activo. No obstante, antes de la mencionada ley no resultaba claro si los consumidores perjudicados por la colusión tenían derecho a impetrar una acción resarcitoria aplicando el procedimiento colectivo del art. 51 de la LPDC ${ }^{46}$.

La duda planteada fue despejada por la reforma de los arts. 30 del DL 211 y 51 de la LPDC realizada por la ley $N^{o} 20.945$. Esta ley concedió competencia al TDLC para conocer la acción indemnizatoria individual o colectiva deducida por los consumidores ante una infracción del DL 211. De manera que hoy resulta indiscutible su legitimación para interponer acciones colectivas destinadas a reparar los perjuicios ocasionados por la colusión. La acción individual se sustancia en el procedimiento sumario general del Código de Procedimiento Civily la colectiva, en el procedimiento contemplado al efecto por la LPDC.

precio, condiciones de contratación y otras características relevantes de los mismos"; de manera que los proveedores que se coluden incumplen su obligación de propiciar el ejercicio de dichos derechos y, por esto mismo, infringen la referida norma de la LPDC.

${ }^{44}$ Araya (2005), p. 11.

${ }^{45}$ Acerca de la historia de la disposición, AraYa (2005), pp. 15-16. El anterior art. 30 (1) del DL 211 consagró la aludida posibilidad en los siguientes términos: "la acción de indemnización de perjuicios a que haya lugar, con motivo de la dictación por el Tribunal de Defensa de la Libre Competencia de una sentencia definitiva ejecutoriada, se interpondrá ante el tribunal civil competente de conformidad a las reglas generales, y se tramitará de acuerdo al procedimiento sumario, establecido en el Libro III del Título XI del Código de Procedimiento Civil".

${ }^{46}$ Ossa y Álvarez (2013), p. 272. Argumentos a favor en Hernández (2017), pp. 646-647. 
En su actual redacción, el art. 30 (1) del DL 211 establece lo siguiente:

"la acción de indemnización de perjuicios a que haya lugar con motivo de la dictación por el Tribunal de Defensa de la Libre Competencia de una sentencia definitiva ejecutoriada, se interpondrá ante ese mismo Tribunal y se tramitará de acuerdo al procedimiento sumario establecido en el Título XI del Libro Tercero del Código de Procedimiento Civil".

Por su parte, tras la ley $\mathrm{N}^{\mathrm{o}} 20.945$, tratándose de los daños causados a los consumidores por la colusión, los incisos penúltimo y último del art. 51 de la LPDC posibilitan la interposición de una acción colectiva para resarcirlos. En particular, el primero prescribe -en lo que importa- que a pesar de lo dispuesto en el art. 30 del DL 211

"y sin perjuicio de las acciones individuales que procedan, la acción de indemnización de perjuicios que se ejerza ante el Tribunal de Defensa de la Libre Competencia, con ocasión de infracciones a dicho cuerpo normativo, declaradas por una sentencia definitiva ejecutoriada, podrá tramitarse por el procedimiento establecido en este Párrafo cuando se vea afectado el interés colectivo o difuso de los consumidores" ${ }^{\prime 7}$.

Aparte de las disposiciones del DL 211 y la LPDC, la responsabilidad civil por los menoscabos causados a los consumidores por la colusión se rige por las normas del Código $\mathrm{Civil}^{48}$.

Naturalmente, el mejor camino para que los consumidores consigan una indemnización es el procedimiento colectivo. Esto se debe a que el individual les impone cargar solos con la dificultosa acreditación de los elementos de la responsabilidad civil, en especial del daño, que -en térmi-

${ }^{47}$ En todo caso, debe tenerse en cuenta el art. quinto transitorio de la ley $\mathrm{N}^{\mathrm{o}} 20.945$, que establece lo siguiente: "las modificaciones introducidas mediante esta ley en el artículo 30 del decreto con fuerza de ley $\mathrm{N}^{\circ}$, de 2004, del Ministerio de Economía, Fomento y Reconstrucción, que fija el texto refundido, coordinado y sistematizado del decreto ley $\mathrm{N}^{\circ} 211$, de 1973, así como aquellas introducidas en el artículo 51 de ley $\mathrm{N}^{\circ} 19.496$, que establece normas sobre protección de los derechos de los consumidores, no regirán respecto de las causas ya iniciadas a la fecha de publicación de la presente ley, las cuales continuarán radicadas en los tribunales competentes a la fecha de inicio de tales causas y proseguirán su sustanciación conforme a lo dispuesto por estos artículos a esa misma fecha, hasta dictarse la respectiva sentencia de término./ Para estos efectos se entenderán como causas ya iniciadas aquellas en las cuales se hubiere notificado la demanda a lo menos a uno de los demandados antes de la publicación de esta ley".

${ }^{48}$ BesOMi (2014), p. 51. 
nos personales- podría no considerarse de magnitud suficiente. Añádase que los costos del juicio podrían superar el monto de la indemnización ${ }^{49}$.

Para que el tribunal admita a trámite una demanda colectiva se deben cumplir los requisitos del art. 52 de la LPDC, a saber:

a) que se deduzca por uno de los legitimados del art. 51 (SERNAC, asociaciones de consumidores o grupo de no menos de cincuenta consumidores) y

b) que contenga una exposición clara de los hechos y fundamentos de derecho que justifican razonablemente la afectación del interés colectivo o difuso de los consumidores ${ }^{50}$.

\section{Presupuestos de LA Legitimación de LOS CONSUMidores PARA DEMANDAR COLECTIVAMENTE INDEMNIZACIÓN DE LOS DAÑOS CAUSADOS POR LA COLUSIÓN}

\section{Preliminar}

La principal cuestión atinente a la legitimación para deducir una acción indemnizatoria colectiva por los daños causados a los consumidores por la colusión es la de sus presupuestos.

En relación con dichos presupuestos me interesa centrarme en dos importantes asuntos. En primer lugar, en el de la exigencia de que los consumidores deban haber contratado con el infractor al efecto de poder deducir una acción colectiva para ser indemnizados por los daños ocasionados por la colusión. En segundo término, en el de la incidencia de la sentencia de libre competencia en el proceso de responsabilidad civil destinado a la obtención de resarcimiento por dichos daños ${ }^{51}$.

${ }^{49}$ Dunne (2015), p. 588; Gómez (2011-2012), p. 97; BÜYüKSAgis (2015), p. 26; CARPAGNANO (2007), p. 16.

${ }^{50}$ Ossa y Állarez (2013), pp. 272-274.

${ }^{51}$ Antes de la ley $\mathrm{N}^{0}$ 20.945, existía la duda de si para deducir la acción colectiva indemnizatoria el demandante (v.gr., el SERNAC) debía haber sido parte del proceso de libre competencia ante el TDLC. El interrogante debía ser respondido negativamente porque el antiguo art. 30 del DL 211 no exigía para la admisibilidad de la acción indemnizatoria que el demandante hubiera sido parte en el proceso sobre libre competencia. Adicionalmente, el art. 52 de la LPDC no menciona la referida exigencia entre los requisitos de admisibilidad de las demandas colectivas. Esta fue la solución dada en el "Caso farmacias" por la Corte de Apelaciones de Santiago, rol No 3908-2013, de 2 de diciembre de 2013, al revocar la resolución del $10^{\circ}$ Juzgado Civil de Santiago (rol No 1940-2013) que había declarado inadmisible la demanda del SERNAC. Véase BESOMI (2014), pp. 168-169. Luego de la reforma de la ley $\mathrm{N}^{\circ} 20.945$ al art. 51 de la LPDC, la duda ha quedado despejada al disponer hoy su inciso final que para interponer la acción 


\section{La exigencia de "vínculo contractual"}

El primer problema, relativo a los presupuestos de la legitimación para deducir una acción colectiva por los daños ocasionados a los consumidores por la colusión, es el de si para su procedencia deben haber celebrado un contrato con el infractor. Al efecto, debe distinguirse, en virtud del art. 50 de la LPDC, entre las acciones para tutelar el interés colectivo -para cuya deducción se exige un "vínculo contractual"- y las acciones para proteger el interés difuso de los consumidores ${ }^{52}$.

El art. 50 (5) de la LPDC asocia la existencia del interés colectivo a la de un vínculo contractual, por lo que solo podrían accionar colectivamente contra el infractor para obtener resarcimiento los consumidores que hayan contratado con él. La norma establece:

"son de interés colectivo las acciones que se promueven en defensa de derechos comunes a un conjunto determinado o determinable de consumidores, ligados con un proveedor por un vínculo contractual”.

Por su parte, el inciso final del artículo dispone:

"para los efectos de determinar las indemnizaciones o reparaciones que procedan, de conformidad a las normas señaladas en el párrafo $2^{\circ}$ de este Título, será necesario acreditar el daño y el vínculo contractual que liga al infractor y a los consumidores afectados".

Así, en caso de colusión, estarían legitimados para deducir la acción colectiva indemnizatoria los consumidores que hayan contratado con el infractor, pero no los que -siendo perjudicados por aquella- no lo hayan hecho.

En mi opinión, el art. 50 de la LPDC no debería exigir la concurrencia de un vínculo contractual para interponer acciones colectivas indemnizatorias en caso de ilícitos contra el mercado, debiendo procederse a su reforma en orden a que conceda legitimación para que puedan deducirlas, también, los consumidores que, pese a no haber contratado con empresas coludidas, hayan celebrado un contrato con un proveedor que, a su turno, lo haya hecho con una de ellas o con otro proveedor (productor, fabricante

indemnizatoria colectiva por los daños ocasionados a los consumidores por un ilícito contra el mercado, "no será necesario que los legitimados activos señalados en el numeral 1 de este artículo se hayan hecho parte en el procedimiento que dio lugar a la sentencia condenatoria".

${ }^{52}$ Cortez (2013), pp. 965-966; Barros (2006), pp. 242-243. 
o distribuidor) de la cadena en que se produjo la colusión (como en el "Caso pollos"). De modificarse en este sentido la norma, los consumidores, para ser indemnizados, deberían acreditar que su proveedor les cargó todo o parte del sobreprecio que a su vez pagó a causa de la colusión ${ }^{53}$.

El apuntado planteamiento es coherente con la concepción asumida por la LPDC en materia de ámbito objetivo de aplicación, conforme a la cual ella rige no solo para las relaciones contractuales sino, también, para las no contractuales y, por consecuencia, en materia de ámbito subjetivo de aplicación al definir las nociones de proveedores y consumidores sin basarse, por lo menos indiscutiblemente, en la necesidad de que se haya celebrado un contrato.

Por lo que concierne a la concepción asumida por la LPDC en materia de ámbito objetivo de aplicación, debe tenerse en cuenta que su artículo 1 (1) señala:

"tiene por objeto normar las relaciones entre proveedores y consumidores, establecer las infracciones en perjuicio del consumidor y señalar el procedimiento aplicable en estas materias”.

Así como la norma no circunscribe su ámbito de aplicación a las relaciones contractuales, puede colegirse que la LPDC rige para ellas y para las no contractuales entre proveedores y consumidores ${ }^{54}$. Las primeras están representadas por los supuestos en que los consumidores han celebrado un contrato con el proveedor al que demandan; y las no contractuales, por aquellos en que se verifica la celebración de un contrato en la cadena de intercambios en que ha participado el consumidor, pero no entre él y el proveedor al que demanda; $y$, también, por aquellos en que no se detecta ningún contrato entre el consumidor y un proveedor, pero sí una relación o contacto con relevancia jurídica entre ellos. Ejemplos de supuestos no contractuales a los que se aplica la LPDC son aquellos en que participan fabricantes, importadores y distribuidores, las relaciones precontractuales (oferta, publicidad, deberes de información, etc.) y los "accidentes de consumo" 55 .

Por su parte, en materia de ámbito subjetivo de aplicación, las definiciones que la LPDC otorga de proveedores y consumidores son congruentes con la concepción asumida por ella en cuanto a su ámbito objetivo de aplicación.

${ }^{53}$ En estos supuestos el proveedor del consumidor podría deducir la acción resarcitoria contra el infractor, surgiendo la discusión relativa a si este podría defenderse aduciendo que no debe indemnizar a dicho proveedor por haber este cargado el sobreprecio al consumidor (defensa passing-on). Cengiz (2010), pp. 43-45; BeAton-Wells (2016), pp. 726-729.

${ }^{54}$ TAPia (2017), p. 76; Isler (2014), pp. 156-157; Momberg (2013), pp. 6-7.

${ }^{55}$ IsLER (2014), pp. 156-157; BARRIENTOS (2014), p. 328. 
El art. 1.2 de la LPDC define proveedores como

"las personas naturales o jurídicas, de carácter público o privado, que habitualmente desarrollen actividades de producción, fabricación, importación, construcción, distribución o comercialización de bienes o de prestación de servicios a consumidores, por las que se cobre precio o tarifa".

Es decir, los sujetos a quienes se aplica la LPDC en cuanto proveedores pueden ser productores, fabricantes, importadores, constructores, distribuidores o comercializadores de bienes o servicios, siendo lo relevante que su actividad esté orientada, de forma directa o indirecta, a los consumidores. De esto surge que algunos puedan estar ligados con el consumidor demandante por un vínculo contractual (comercializadores) y otros no necesariamente (productores, fabricantes, constructores, importadores y distribuidores $)^{56}$.

Por lo que atañe a los consumidores, el art. 1.1 de la LPDC los define como

"las personas naturales o jurídicas que, en virtud de cualquier acto jurídico oneroso, adquieren, utilizan, o disfrutan, como destinatarios finales, bienes o servicios".

Además, el artículo 9 de la ley $\mathrm{N}^{\mathrm{o}} 20.416$, de 2010, considera consumidores a las empresas de menor tamaño al efecto de aplicarles diversas disposiciones de la LPDC. Conforme a lo indicado, la LPDC considera consumidores tanto a quienes -como destinatarios finales- contratan con el proveedor (adquieren) como a quienes utilizan o disfrutan bienes o servicios, que pueden haber contratado o no con el infractor, criterio que ha sido corroborado por nuestros tribunales ${ }^{57}$.

En relación con lo anterior, cabe tener en cuenta que hoy tiende a imponerse una noción de consumidor amplia, que engloba tanto al consumidor jurídico como al material, que ha sido ratificada por buena parte de la jurisprudencia. El primero es el vinculado contractualmente con el proveedor (el que adquiere) y, el segundo, el que consume sin haber necesariamente celebrado un contrato con un proveedor (el que utiliza o disfru$t a)^{58}$.

${ }^{56}$ Barrientos (2010), p. 28.

${ }^{57}$ Momberg (2013), pp. 6-7; TAPia (2017), pp. 42-51.

${ }^{58}$ Isler (2014), pp. 156-157; Barrientos (2014), p. 328; TAPIA (2017), pp. 51-56; Momberg (2013), pp. 7-8. 
Así, para que una relación dé lugar a la tramitación de un juicio regido por la LPDC, el demandante debe ser consumidor y el demandado, proveedor, haya o no mediado un contrato entre ambos ${ }^{59}$.

Ahora bien, contrariamente a lo establecido por el art. 50 de la LPDC, la directiva 2014/104/UE, respecto de la indemnización por el daño provocado por un atentado contra el mercado, señala:

"el derecho a resarcimiento está reconocido para cualquier persona física o jurídica (consumidores, empresas y administraciones públicas) con independencia de la existencia de una relación contractual directa con la empresa infractora" (considerando 13).

La precedente solución fue seguida por el Tribunal de Justicia de la Unión Europea en Kone AG and Others v. ÖBB-Infrastruktur AG (2014) al concluir:

"la plena efectividad del artículo 101 TFUE resultaría menoscabada si el derecho de cualquier persona a solicitar la reparación del perjuicio sufrido quedara subordinado por el Derecho nacional, de manera categórica e independientemente de las circunstancias específicas del caso, a la existencia de una relación de causalidad directa, excluyendo tal derecho debido a que la persona en cuestión ha tenido vínculos contractuales, no con un miembro del cártel, sino con una empresa no participante en éste, cuya política de precios, no obstante, es una consecuencia del cártel que ha contribuido a falsear los mecanismos de formación de los precios que rigen en los mercados competitivos" (apartado 33) ${ }^{60}$.

Por su parte, en lo que concierne al interés difuso, en virtud del art. 50 (6) de la LPDC, están encaminadas a tutelarlo "las acciones que se promueven en defensa de un conjunto indeterminado de consumidores afectados

${ }^{59}$ Adicionalmente, la propuesta de reforma destinada a no exigir la acreditación de un vínculo contractual para que los consumidores demanden colectivamente por los daños que hayan padecido producto de la colusión, contribuiría a evitar el enriquecimiento injustificado de los proveedores concertados (apropiación del sobreprecio cobrado) en caso de que no sean demandados por los consumidores (cuando no estén ligados contractualmente con ellos) ni por otros agentes, ante lo cual cabe tener presente que no se contemplan en la LPDC acciones colectivas por un enriquecimiento de aquel tipo. Besomi (2014), pp. 30-31. A mayor abundamiento, el principio pro consumidor conduciría a proteger tanto a los consumidores contratantes como a los no contratantes. Momberg (2013), p. 8. Acerca de dicho principio, Guillén (2002), pp. 185-227; SALELles (2009), pp. 232-233.

${ }^{60}$ Dunne (2015), p. 587. 
en sus derechos". Así, están legitimados para demandar indemnización los consumidores que hayan decidido no contratar con las empresas coludidas por no aceptar pagar el sobreprecio cobrado o por no tener recursos para hacerlo y que a consecuencia de ello hayan resultado perjudicados. De suerte que los consumidores que contrataron con proveedores distintos de las empresas concertadas, que no estarían legitimados para deducir la acción colectiva indemnizatoria, por no ligarlos un vínculo contractual con el infractor, podrían interponer una para salvaguardar su interés difuso al constituir frente al infractor un conjunto indeterminado de consumidores afectados en sus derechos. De no dárseles esta alternativa quedarían sin poder ejercer, en forma colectiva, su derecho a ser indemnizados.

\section{Incidencia de la sentencia de libre competencia en el proceso de responsabilidad civil}

El segundo asunto problemático relacionado con los presupuestos de la legitimación de los consumidores en este terreno es el de la incidencia de la sentencia de libre competencia en el proceso de responsabilidad civil por los menoscabos que hayan sufrido en virtud de la colusión.

En orden a abordar el punto, debe tenerse en cuenta que el art. 30 (2) 104 del DL 211 dispone:

"al resolver sobre la acción de indemnización de perjuicios, el Tribunal de Defensa de la Libre Competencia fundará su fallo en los hechos establecidos en su sentencia que sirvan de antecedente a la demanda".

Por su parte, el art. 51 de la LPDC establece:

"la acción de indemnización de perjuicios que se ejerza ante el Tribunal de Defensa de la Libre Competencia, con ocasión de infracciones a dicho cuerpo normativo, declaradas por una sentencia definitiva ejecutoriada, podrá tramitarse por el procedimiento establecido en este Párrafo cuando se vea afectado el interés colectivo o difuso de los consumidores".

La primera cuestión a reflexionar en relación con la referida incidencia de la sentencia de libre competencia es la de si para la interposición por los consumidores de la acción colectiva indemnizatoria de los perjuicios ocasionados por la colusión es indispensable que cuenten con dicha sentencia ${ }^{61}$. p. 966.

${ }^{61}$ El mismo interrogante se planteaba antes de la ley $\mathrm{N}^{0} 20.945$. Fuch y VIVEs (2015), 
En principio, de acuerdo con el art. 51 de la LPDC, la sentencia ejecutoriada de libre competencia del TDLC sería un presupuesto indispensable al efecto de incoar el procedimiento indemnizatorio colectivo (lo mismo puede desprenderse del art. 30 del DL 211, respecto del individual); habiéndose adoptado en nuestro medio, así, el modelo de las follow-on actions ${ }^{62}$.

Entre las ventajas del señalado modelo destaca el beneficio del efecto reflejo o función positiva o prejudicial de la cosa juzgada, en cuya virtud, en el proceso por responsabilidad civil siguiente a la sentencia de libre competencia se asume como indiscutible todo o una parte significativa de lo contenido en ella, pudiendo debatirse en él solo respecto del concreto daño padecido por los afectados y la causalidad ${ }^{63}$.

Así, en Estados Unidos -de acuerdo con la sección 5 (a) de la Sherman Act- las sentencias dictadas en un procedimiento por ilícito contra el mercado son un medio de prueba irrebatible en el juicio civil posterior. Y, en Reino Unido, conforme a la sección 58 A de la Competition Act (1998), la declaración de una conducta como anticompetitiva provoca el efecto de cosa juzgada en el juicio indemnizatorio que se incoe después.

Ahora bien, pese a la aparente claridad de la redacción del art. 51 de la LPDC (y 30 del DL 211), considero que no es concluyente en orden a que para deducir la acción indemnizatoria por los daños padecidos por los consumidores producto de la colusión deban contar necesariamente con la sentencia ejecutoriada de libre competencia del TDLC.

En mi opinión, dicha sentencia se requiere solo para incoar el juicio indemnizatorio colectivo (o individual) ante TDLC y contar con el beneficio del efecto reflejo de la cosa juzgada (y, tratándose de la acción individual, con el procedimiento sumario). De manera que, pese a no disponer los consumidores de la aludida sentencia, igual podrían accionar en forma colectiva (o individualmente) ante el tribunal civil competente, pero en este caso no contarían con el referido beneficio, debiendo probar en el proceso correspondiente todos los requisitos de la responsabilidad civil $^{64}$.

Adicionalmente, que de la redacción del art. 51 de la LPDC (y de la del 30 del DL 211, referido a las acciones individuales) puede desprenderse que la sentencia condenatoria ejecutoriada del TDLC se requiere solo en los casos en que este tribunal haya intervenido para determinar si se ha

${ }^{62}$ Lewin (2011), p. 44; Domínguez (2017), p. 611; Besomi (2014), p. 55. Respecto de algunos ordenamientos en que se aplica este modelo, KuijPers (2015), pp. 3-10.

${ }^{63}$ Lewin (2011), p. 45; Fuch y Vives (2015), pp. 965 y 967. Una desventaja del mecanismo adoptado en Chile consiste en que el TDLC no es un tribunal especializado en juicios indemnizatorios. VALDÉs (2009), pp. 279-280; Domínguez (2017), pp. 615-616.

${ }^{64}$ Besomi (2014), pp. 175-178. 
producido un atentado contra el mercado -como el de colusión-, caso en el cual dicha sentencia sería esencial para iniciar el juicio de responsabilidad civil ante aquel tribunal. Así, de no haber intervenido el TDLC y dictado, por tanto, una sentencia, los consumidores perjudicados podrían deducir la acción resarcitoria colectiva ante un juzgado civil ${ }^{65}$.

A la luz de la interpretación alternativa que propongo del art. 51 de la LPDC (y 30 del DL 211), nuestra legislación habría optado -al menos en parte- por el modelo de las stand alone actions ${ }^{66}$.

Una de las ventajas del modelo de las stand alone actions es que en los casos en que la autoridad persecutora de los ilícitos anticompetitivos decida no perseguirlos o no continuar el proceso entablado por no considerarlo relevante o por otras razones (supuestos en que no habrá sentencia del TDLC), igualmente los perjudicados podrían demandar indemnización ante el tribunal competente ${ }^{67}$. Una hipótesis así podría presentarse si se celebra un acuerdo con estatus de equivalente jurisdiccional (v.gr., una conciliación) entre la autoridad y el infractor ${ }^{68}$. Un supuesto semejante podría presentarse, asimismo, si aquella desiste de la persecución por considerar que la acción está prescrita (como hizo la FNE en el "Caso pañales"). En ambas hipótesis los consumidores igualmente podrían ejercer la acción resarcitoria ante el tribunal competente ${ }^{69}$.

106 Las desventajas del modelo de las stand alone actions son que un órgano no especializado en libre competencia dictamina acerca de la materialización de un ilícito antitrust, los posibles pronunciamientos contradictorios, la aplicación del forum shopping y la necesidad de que los perjudicados acrediten en el proceso indemnizatorio todos los elementos de la responsabilidad civil, incluido el ilícito contra el mercado ${ }^{70}$.

${ }^{65}$ Kujjers (2015), pp. 10-14.

${ }^{66}$ En contra, Barros (2006), p. 1047; Besomi (2014), p. 178.

${ }^{67}$ BANFI (2013), pp. 232-233; FRÊNE (2011), pp. 83-84.

${ }^{68}$ FrêNe (2011), pp. 80-81 y 83-84.

${ }^{69}$ Considerando que el art. 20 (final) del DL 211 establece que el plazo de prescripción de la acción indemnizatoria es de cuatro años contados desde que esté firme la sentencia del TDLC, habría que concluir que este plazo rige para los casos en que exista la referida sentencia, sin que opere para los supuestos en que no lo haga, en que regiría el plazo establecido por el Código Civil. Con respecto al plazo de prescripción, una interesante fórmula para iniciar su conteo es la establecida en el art. 10.2 de la directiva 2014/104/ UE, que señala: "los plazos no empezarán a correr antes de que haya cesado la infracción del Derecho de la competencia y el demandante tenga conocimiento, o haya podido razonablemente tener conocimiento de: a) la conducta y el hecho de que sea constitutiva de una infracción del Derecho de la competencia;/ b) que la infracción del Derecho de la competencia le ocasionó un perjuicio, y / c) la identidad del infractor”.

${ }^{70}$ Fuch y Vives (2015), pp. 970-973. En Sound Colour con United International Pictures Chile (2009), luego de que el TDLC no estimara concurrente una infracción 
Otro asunto relativo a la incidencia de la sentencia de libre competencia en el juicio indemnizatorio de los detrimentos padecidos por los consumidores producto de la colusión es que, de acuerdo con el art. 30 (2) del DL 211, en dicho juicio la sentencia ejecutoriada del TDLC genera cosa juzgada en relación con los hechos, a cuyo respecto no puede ya debatirse, si bien se mantiene la posibilidad de discutir sobre los demás elementos de la responsabilidad civil. Pese a que el art. 51 de la LPDC (referido a las acciones colectivas) nada dice al respecto, considerando la remisión que hace al art. 30 del DL 211, debería asumirse que el apuntado efecto reflejo de cosa juzgada también rige para el juicio colectivo.

En relación con lo anterior y sin perjuicio de que en el siguiente punto profundizaré al respecto, cabe consignar que el actual art. 30 (2) del DL 211 difiere del anterior, por cuanto, antes de la ley $\mathrm{N}^{\mathrm{o}} 20.945$, el efecto reflejo de la cosa juzgada en este ámbito estaba asociado a la conducta, los hechos y la calificación jurídica de estos, y no solo a los hechos ${ }^{71}$.

\section{CulPabilidad Y DaÑo}

\section{Preliminar}

Según se sabe, para que haya lugar a la responsabilidad civil se exige una conducta voluntaria, culpabilidad, daño y causalidad ${ }^{72}$.

En relación con el tipo de pleito sobre el que versa este trabajo me interesa formular diversas consideraciones acerca de la culpabilidad y el daño, que son los requisitos que mayores problemas suscitan ${ }^{73}$.

\section{Culpabilidad}

Por lo refiere a la culpabilidad, cabe tener presente que los ilícitos contra la competencia suelen distinguirse por su carácter doloso. Esto significa que la conducta del infractor se considera deliberada ${ }^{74}$.

En cuanto a la negligencia, debe recordarse, en primer término, que la culpa grave se equipara al dolo (art. 44 del Código Civili) ${ }^{75}$. Por su parte,

antimonopólica entre competidores, la Corte de Apelaciones de Santiago desechó aplicar el señalado mecanismo. Eso sí, el proceso se tramitó antes de la ley $\mathrm{N}^{\mathrm{o}} 20.945$, que reformó los arts. 30 del DL 211 y 51 de la LPDC.

${ }^{71}$ LeWin (2011), pp. 45-46; CORRAL (2013), p. 330.

${ }^{72}$ Abeliuk (2014), p. 255; Corral (2013), pp. 99-100.

${ }^{73}$ Berenguer (2011), p. 59.

${ }^{74}$ Besomi (2014), pp. 144-145; Banfi (2014), pp. 40-41.

${ }^{75}$ BANFi (2014), p. 41. 
también podría considerarse que en este terreno el factor de imputabilidad puede ser, aparte de la culpa grave, otro tipo de negligencia, representado por la inobservancia de la conducta que habría desplegado un empresario prudente ${ }^{76}$.

Ahora bien, antes de la ley No 20.945, el art. 30 del DL 211 establecía que la sentencia firme del TDLC provoca cosa juzgada en el proceso resarcitorio respecto de los hechos, la conducta y su calificación jurídica. Tras dicha ley, el art. alude exclusivamente a los hechos. Pese a que el art. 51 de la LPDC (referido a las acciones colectivas) nada dice al respecto, considerando la remisión que hace al art. 30 del DL 211, podría asumirse que el apuntado efecto reflejo de cosa juzgada también rige para el juicio colectivo.

Conforme al anterior art. 30 del DL 211, en la medida de que la sentencia condenatoria sobre libre competencia se pronuncia acerca de la conducta y la calificación jurídica, debía entenderse que en el juicio sobre responsabilidad civil por los daños derivados de la colusión, no resultaba necesario probar la culpabilidad, por haberse acreditado en el de libre competencia, debiendo el demandante comprobar solo el daño y la causalidad ${ }^{77}$.

Teniendo en cuenta que de acuerdo con el actual art. 30 del DL 211 el 108 efecto de cosa juzgada de la sentencia de libre competencia en el proceso indemnizatorio se extiende exclusivamente a los hechos, podría concluirse que los consumidores deben acreditar la culpabilidad del infractor en dicho proceso $^{78}$.

No estoy de acuerdo con dicha interpretación. Esto se debe a que ella implicaría un retroceso en la situación de los consumidores al quedar en una posición inferior a la que tenían antes de la ley $\mathrm{N}^{\mathrm{o}} 20.945$. Además, supondría ir contra el propósito del legislador de incentivar las acciones de responsabilidad civil como vía de fomento del cumplimiento de las normas sobre libre competencia ${ }^{79}$. A mayor abundamiento, habiéndose comprobado la culpabilidad del infractor en el juicio sobre libre competencia sustanciado ante el TDLC, no sería razonable que en el proceso civil seguido ante el mismo tribunal los consumidores tuvieran que acreditar nuevamente la culpabilidad. Evitar esta prueba es el sentido de lo dispuesto por el art. 30 del DL 211. Luego, cabe tener a la vista que la colusión es un ilícito descrito por dicho DL precisamente en torno a la

${ }^{76}$ VALDÉS (2009), pp. 281-282.

77 Barros (2006), p. 1047; Corral (2013), p. 330; Domínguez (2017), pp. 608-609; BANFI (2014), p. 41; BESOMI (2014), p. 58.

${ }^{78}$ Domínguez (2017), p. 618.

${ }^{79}$ BANfi (2014), p. 42. 
culpabilidad de la conducta, de manera que al materializarse aquella puede darse por verificada la culpabilidad en el proceso civil ${ }^{80}$, más aún considerando que en buena parte de los casos reseñados al comienzo los infractores han confesado su conducta ilícita. En fin, el último inciso del art. 50 de la LPDC dispone:

"para los efectos de determinar las indemnizaciones o reparaciones que procedan, de conformidad a las normas señaladas en el párrafo $2^{\circ}$ de este Título, será necesario acreditar el daño y el vínculo contractual que liga al infractor y a los consumidores afectados".

Así, a la luz del precepto, el único requisito de la responsabilidad civil que debe acreditarse en el proceso resarcitorio colectivo es el daño, sin que sea necesario, por tanto, comprobar la culpabilidad.

En todo caso, de concluirse que la culpabilidad debe acreditarse en el proceso resarcitorio, los demandantes podrían valerse al efecto de cualquier medio de prueba legal.

Como es lógico, lo anterior se aplica al dolo (art. 1459 del Código Civil), sin perjuicio de que su concurrencia pueda darse por acreditada vía presunción judicial a partir de la prueba de un daño directo a los consumidores $^{81}$.

Por lo que concierne a la negligencia, sin perjuicio de la utilización de todos los medios legales de prueba, deberían tener un papel destacado, en su caso, la figura de la culpa en la organización, las presunciones de culpa por el hecho propio (art. 2329 del Código Civil) y el ajeno (arts. 2320 y 2322 del Código Civil) y la presunción de culpa por infracción de un deber de comportamiento establecido en la ley, como el DL 211 (culpa infraccional). Así, habiéndose acreditado la colusión, debería tenerse por comprobada la culpabilidad $^{82}$.

\section{Daño indemnizable}

a) Preliminar

Conforme anticipara, en términos sociales, el daño causado por la colusión es el menoscabo al mercado o antitrust en sí, representado por la merma de las transacciones o de la eficiencia económica (deadweight welfare loss), que no resulta indemnizable; constituyendo, así, un detrimento diferente del

\footnotetext{
${ }^{80}$ Besomi (2014), p. 59.

${ }^{81}$ BANFi (2014), pp. 42-43.

${ }^{82}$ Barrientos (2010), pp. 112-114; Barros (2006), pp. 98-100 y 1045; Banfi (2014), pp. $41-42$.
} 
provocado a los consumidores en particular ${ }^{83}$. Este último, que, reuniendo determinados requisitos, sí resulta indemnizable ${ }^{84}$, está representado por el que padecen los consumidores en concreto producto de la infracción al derecho de la competencia, siendo la partida más destacada, en el caso de la colusión, el sobreprecio pagado (overcharge), consistente en la diferencia entre el precio de mercado y el colusivo ${ }^{85}$.

En cuanto a los requisitos del daño indemnizable, cabe recordar, en primer término, que debe constituir una afectación de un interés legítimo, ostentar magnitud suficiente o anormal, ser cierto y estar conectado directamente con la conducta dañosa, en este caso, la colusión ${ }^{86}$. En segundo lugar, en el juicio de responsabilidad civil se deberá acreditar su existencia, naturaleza y cuantía, así como su relación causal directa con aquella ${ }^{87}$. En tercer término, ha de tenerse presente que la apreciación de la prueba en este tipo de proceso se rige por el sistema de la sana crítica, en virtud de los arts. 30 del DL 211 y 51 de la LPDC ${ }^{88}$.

\section{b) Categorías de intereses afectados}

Considerando que estamos en el terreno de las acciones colectivas, un aspecto fundamental a tener presente en relación con la comprobación de la existencia, naturaleza y monto de los perjuicios y la relación de 110 causalidad, es que el tribunal deberá formar grupos y subgrupos de perjudicados (art. 53 A de la LPDC), según las diversas categorías de intereses afectados por el daño.

Así, teniendo en cuenta que el ilícito de que se trata es el de colusión, el juzgador debería diferenciar entre los consumidores que contrataron con un infractor (pagando un sobreprecio) y los que no contrataron con uno. A su turno, entre estos debería distinguir entre los que, a consecuencia del sobreprecio que se les pretendió cobrar, no contrataron con ningún proveedor y los que contrataron con un proveedor no infractor. Entre estos últimos, a su vez, debería distinguir entre los que contrataron a un precio superior al de mercado, en virtud del "efecto paraguas"; y los que contrataron menos bienes de los que necesitaban o de inferior calidad ${ }^{89}$.

Para la acreditación de la existencia, naturaleza y monto de los concretos perjuicios padecidos a consecuencia de la colusión, así como para

${ }^{83}$ Eyzaguirre y Grunberg (2008), p. 59; Banfi (2013), pp. 224-225; Lewin (2011), p. 46.

${ }^{84}$ Domínguez (2017), pp. 608-609.

${ }^{85}$ Cavanagh (2010), p. 632; Lewin (2011), pp. 46-48.

${ }^{86}$ Abeliuk (2014), pp. 288-293; Barros (2006), p. 236 y ss.; Corral (2013), pp. 135141; Diez (2012), p. 30 y ss.; Domínguez (2017), p. 609.

${ }^{87}$ Carpagnano (2007), pp. 11 y 15; Valdés (2009), p. 279.

${ }^{88}$ Una crítica a la aplicación de este sistema en este terreno en Domínguez (2017), p. 617.

${ }^{89}$ Araya (2005), p. 26. 
la de su relación causal con ella, los consumidores pueden emplear todos los medios legales, por ejemplo, documentos (v.gr., boletas) y, en su caso, testigos ${ }^{90}$.

Todo lo anterior ha de entenderse sin perjuicio de que, en aplicación del art. 54 de la LPDC, la sentencia que declare la responsabilidad del demandado opera con efecto absoluto, pudiendo todos los consumidores perjudicados reclamar las correspondientes indemnizaciones, incluso, los que no hayan participado en el proceso. Estos, que no habrán rendido prueba de sus menoscabos, podrán beneficiarse de la acreditación judicial de daños estandarizados para cada grupo y subgrupo de consumidores efectuada por quienes hayan concurrido al pleito, siempre que se presenten oportunamente a hacer valer sus derechos y sin perjuicio del que tienen para solicitar resarcimiento en otro proceso en caso de haber hecho reserva de acciones ${ }^{91}$.

\section{c) Naturaleza}

\section{i) Daño patrimonial}

En cuanto a la naturaleza del daño indemnizable, cabe apuntar que, aun cuando el art. 30 del DL 211 no se refiere a ella, siguiendo las reglas generales, se debe reparar, ante todo, el detrimento patrimonial padecido por los consumidores a causa de la colusión ${ }^{92}$, representado, principalmente, por el sobreprecio pagado ${ }^{93}$.

Pese a que conforme a dichas reglas se puede postular sin problema la indemnizabilidad de los daños patrimoniales, en caso de operar colusión, en una fórmula regulatoria avanzada se ha preferido dejar expresa constancia de esta alternativa. Así, la directiva 2014/104/UE, en su considerando 12, prescribe:

"cualquier persona que haya sufrido un perjuicio ocasionado por tal infracción puede solicitar resarcimiento por el daño emergente (damnum emergens), el lucro cesante (pérdida de beneficios o lucrum cessans) más los intereses (...)".

${ }^{90}$ Acerca de la prueba del daño, Diez (2012), pp. 133-140.

${ }^{91}$ Respecto del art. 54 de la LPDC, AguirrezÁBAL (2013b), pp. 1046-1051. Cabe tener en cuenta, asimismo, que el art. $53 \mathrm{C}$ c) de la LPDC establece que la sentencia condenatoria deberá "declarar la procedencia de las correspondientes indemnizaciones o reparaciones y el monto de la indemnización o la reparación a favor del grupo o de cada uno de los subgrupos, cuando corresponda”.

${ }^{92}$ Domínguez (2017), p. 618.

${ }^{93}$ Cavanagh (2010), p. 632; Lewin (2011), pp. 46-48; Besomi (2014), p. 102. 
En concreción de lo señalado, el art. 12.2 y 3 establece expresamente en este ámbito la indemnizabilidad del daño emergente y el lucro cesante.

Así, dentro de los perjuicios patrimoniales ocasionados a los consumidores por la colusión, se debe indemnizar, en primer término, el daño emergente, representado -en su caso- por el sobreprecio pagado a los infractores ${ }^{94}$. También se les debería indemnizar por el sobreprecio pagado a los no infractores a consecuencia del "efecto paraguas", consistente en el alza de precio efectuada por las empresas no coludidas producto de la subida realizada por las concertadas ${ }^{95}$. Ambos son daños puramente patrimoniales en cuanto no lesionan ni a una persona ni a una cosa corporal ${ }^{96}$.

Asimismo, es posible concebir hipótesis de indemnización del daño padecido por los consumidores que no hayan podido adquirir el producto cuyo precio fue incrementado concertadamente. Sería el caso, v. gr. -pensando en uno como el de las "Farmacias"-, de los que no pudieron comprar los medicamentos para tratar sus dolencias y tuvieron que adquirir otros o realizarse procedimientos médicos conectados causalmente con la imposibilidad de comprar generada por la colusión ${ }^{97}$.

Luego, dentro de los daños patrimoniales ocasionados a los consumidores por un ilícito anticompetitivo, debería resarcirse, en su caso, el lucro cesante que hayan padecido, esto es, la pérdida de rendimientos económicos generada por el pago de un sobreprecio ${ }^{98}$.

Por cierto, todo lo anterior deben sumarse los reajustes e intereses ${ }^{99}$.

${ }^{94}$ Waelbroeck, Slater y Even-Shoshan (2004), p. 105; Carpagnano (2007), p. 17; Besomi (2014), p. 65.

${ }^{95}$ Dunne (2015), p. 582; BüYÜKsagis (2015), p. 23. En Kone AG and Others v. ÖBBInfrastruktur AG (2014), el Tribunal de Justicia de la Unión Europea señaló lo siguiente: "la víctima de un efecto paraguas sobre los precios ('umbrella pricing') puede obtener de los miembros de un cártel la reparación del daño sufrido, aun cuando no haya tenido vínculos contractuales con ellos, en la medida en que se acredite que, según las circunstancias del caso y, en particular, conforme a las especificidades del mercado en cuestión, dicho cártel podía tener como consecuencia que terceras partes, actuando de manera autónoma, aplicaran precios aprovechando la concertación, y que tales circunstancias y especificidades no podían ser ignoradas por los miembros del cártel. Corresponde al órgano jurisdiccional remitente comprobar si se satisfacen estas condiciones" (apartado 34).

${ }^{96}$ Barros (2006), p. 283.

${ }^{97}$ Se trata de un daño de difícil prueba en cuanto a su existencia y conexión causal directa con el ilícito, por lo que suele opinarse contra su indemnizabilidad. No obstante, de probarse -conforme a la estandarización de perjuicios que rige en este terreno-, debería resarcirse. BESOMI (2014) pp. 103 y 128-131.

${ }^{98}$ Naturalmente, su acreditación resultará difícil. Podría ser el caso, por ejemplo, del interés dejado de percibir por la colocación bancaria del dinero pagado como sobreprecio. Carpagnano (2007), p. 17.

${ }^{99}$ Abeliuk (2014), pp. 402-403; Corral (2013), pp. 143-146; Diez (2012), p. 192 y ss. 


\section{ii) Daño extrapatrimonial}

Por lo que concierne al daño extrapatrimonial provocado por la colusión a los consumidores, indudablemente, debería repararse en los procedimientos indemnizatorios individuales, en aplicación del art. 3 e) de la LPDC, de ser procedente conforme a los principios y reglas de la responsabilidad civil ${ }^{100}$.

En el caso del procedimiento indemnizatorio colectivo, el art. 51.2 de la LPDC establece que el daño moral no se indemniza. Se trata de una solución que, aun cuando pueda justificarse por la complejidad de este tipo de resarcimiento en sede de acciones colectivas, resulta cuestionable porque el art. 3 e) de dicha ley consagra ampliamente el derecho de los consumidores a la indemnización (incluyendo la del daño moral) y porque implica dar lugar a una diferenciación infundada respecto de los que entablen acciones individuales.

En relación con lo anterior, cabe referir que en virtud de la reciente aprobación por el Congreso Nacional del proyecto de ley que modifica la LPDC, su nuevo art. 51.2, establecerá, respecto del procedimiento colectivo, que:

"las indemnizaciones que se determinen en este procedimiento podrán extenderse al daño moral siempre que se haya afectado la integridad física o síquica o la dignidad de los consumidores" ${ }^{101}$.

Así, con la entrada en vigencia de la mencionada modificación, los consumidores podrían aspirar a indemnización por los daños extrapatrimoniales ocasionados por la colusión, v.gr., por atentados contra su integridad física o psíquica o su dignidad. A modo de ejemplo -pensando en el "Caso farmacias"-, de haber existido una norma como la referida al momento de originarse los hechos que lo motivaron, los consumidores que no pudieron adquirir remedios para tratar sus enfermedades, podrían haber obtenido resarcimiento del daño extrapatrimonial por la agravación de sus patologías o por los nuevos menoscabos a la salud padecidos como consecuencia directa de la colusión ${ }^{102}$.

${ }^{100}$ En general, Contardo (2013), p. 126.

${ }^{101} \mathrm{El}$ proyecto de ley que dio lugar a esta reforma se originó en el Boletín $\mathrm{N}^{\circ}$ 9.369-03.

${ }^{102}$ La sentencia de la Corte Suprema pronunciada en Requerimiento de la FNE contra Farmacias Ahumada S.A. y otros (2012), dejó entrever esta posibilidad al señalar en su c. nonagésimo que "el interés económico se sobrepuso a la dignidad humana, a la vida y a la salud de las personas". 


\section{d) Cuantificación}

En lo concerniente a la cuantificación general del daño, cabe tener en cuenta que si en la sentencia del TDLC ha quedado constancia de ella o de las bases para determinarla, en el procedimiento resarcitorio deberían considerarse probadas, sin que corresponda exigir nuevamente su comprobación $^{103}$.

Como es lógico, lo anterior debe entenderse sin perjuicio de que los daños concretos sufridos por los consumidores producto de la colusión sí deben probarse en el juicio indemnizatorio ${ }^{104}$. Según señalara, esta comprobación estará referida a cada grupo o subgrupo de consumidores formado por el tribunal en aplicación del art. 53 A de la LPDC, debiendo haber lugar, de este modo, a una estandarización del daño indemnizable al interior de cada categoría. Así, con la sentencia (art. 54 de la LPDC), todos los consumidores perjudicados podrán reclamar las correspondientes indemnizaciones, incluso los que no hayan tomado parte en el proceso. De manera que estos, pese a no haber rendido prueba de sus detrimentos, podrán beneficiarse de la comprobación judicial de menoscabos estandarizados para cada grupo y subgrupo de consumidores realizada por quienes hayan concurrido al proceso, siempre que se presenten oportunamente a hacer valer sus derechos y sin perjuicio del que tienen para pedir in114 demnización en otro juicio en caso de haber hecho reserva de acciones.

Por lo que atañe en particular a la cuantía de los concretos daños padecidos por los consumidores a consecuencia de la colusión, cabe tener presente que, en aplicación del art. 30 del DL 211, debe abarcar todos los perjuicios provocados en el periodo en que se haya extendido aque$11 a^{105}$.

Luego, ha de tenerse presente que en Chile el principio de reparación integral del daño y la función compensatoria de la responsabilidad civil conducen a que los consumidores perjudicados por la colusión deban ser indemnizados por todos los menoscabos concretos que hayan padecido, ni más ni menos ${ }^{106}$.

No obstante, algunos ordenamientos regulan la institución de los daños punitivos, v.gr., para los supuestos de ilícito anticompetitivo, de manera que el infractor pague a los perjudicados, a título de indemnización, en

${ }^{103}$ Domínguez (2017), p. 611. Por ejemplo, en la sentencia de la Corte Suprema pronunciada en Requerimiento de la FNE contra Farmacias Ahumada S.A. y otros (2012) ha quedado constancia de la cuantía del daño sufrido por el conjunto de los consumidores (c. septuagésimo séptimo y octagésimo sexto).

${ }^{104}$ BANFi (2013), p. 240.

105 Domínguez (2017), p. 609.

${ }^{106}$ Diez (2012), pp. 159-161; Barros (2006), p. 216. 
orden a la satisfacción de una finalidad preventiva y disuasoria, un monto sustantivamente superior al del daño ${ }^{107}$.

Conforme a lo adelantado, para la acreditación del monto de los concretos perjuicios padecidos a consecuencia de la colusión, los consumidores pueden emplear todos los medios legales, por ejemplo, documentos (v.gr., boletas) y, en su caso, testigos ${ }^{108}$.

Aparte de los señalados medios, el concreto daño provocado por la colusión a los consumidores podría ser acreditado mediante presunciones. Se trata de un medio que en este tipo de juicios es especialmente relevante por descargar a los consumidores de la necesidad de recabar pruebas detalladas, que generalmente no están a su disposición, sino de los infractores. El protagonismo de las presunciones en este ámbito permite dar operatividad al derecho de los consumidores a la indemnización, consagrado en el art. 3 e) de la LPDC.

Ilustrativa en el anterior sentido es la directiva 2014/104/UE, que en su considerando 14 señala lo siguiente:

"las acciones por daños ocasionados por infracciones del Derecho de la competencia de la Unión o nacional suelen exigir un análisis fáctico y económico complejo. Las pruebas que se necesitan para acreditar una reclamación de daños y perjuicios suelen estar exclusivamente en posesión de la parte contraria o de terceros, y no son conocidas suficientemente por el demandante o no están a su alcance. En tales circunstancias, el establecimiento de estrictos requisitos legales que exijan de los demandantes hacer valer en detalle todos los hechos del caso y aportar elementos de prueba muy específicos al inicio de una acción, puede obstaculizar indebidamente el ejercicio efectivo del derecho a resarcimiento garantizado por el TFUE”.

${ }^{107}$ Hamilton y Henry (2012), p. 113; Banfi (2013), p. 225 y ss.; Cavanagh (2010), pp. 631-636; Carpagnano (2007), p. 16; Waelbroeck, Slater y Even-Shoshan (2004), p. 130. La directiva 2014/104/UE optó por rechazar expresamente su aplicación al disponer su art. 3.3: "el pleno resarcimiento con arreglo a la presente Directiva no conllevará una sobrecompensación, bien mediante indemnizaciones punitivas, múltiples o de otro tipo”. Anteriormente, el Tribunal de Justicia de la Unión Europea había dejado abierta la posibilidad de aplicar daños punitivos en la sentencia pronunciada en Manfredi y Lloyd v. Adriatico Assicurazioni SpA (2006), cuyo apartado 93 señala: “de acuerdo con el principio de equivalencia, en las acciones basadas en las normas comunitarias de la competencia deben poder concederse indemnizaciones especiales, como son las de carácter disuasorio o punitivo, si tales indemnizaciones pueden concederse en acciones similares basadas en el Derecho interno".

${ }^{108}$ Acerca de la prueba del daño, Diez (2012), pp. 133-140. 
En coherencia con lo apuntado, el art. 17.2 establece:

"se presumirá que las infracciones de cárteles causan daños y perjuicios. Al infractor le asistirá el derecho a rebatir esa presunción”.

Entre los fundamentos de la referida presunción destaca que frecuentemente los proveedores víctimas de ilícitos anticompetitivos imponen a los consumidores los sobrecostos que han sufrido, así como las dificultades de acceso a la información padecidas por los segundos, que obstaculizan sobremanera la prueba del daño ${ }^{109}$.

Ahora bien, teniendo en cuenta que en este tipo de procesos no resultaría apropiado exigir una prueba exhaustiva de la cuantía del daño, debería aceptarse -en orden a su resarcimiento- una estimación razonable ${ }^{110}$. Así, las dificultades para determinar el monto del perjuicio -considerando que se fundan en el ilícito cometido por el infractor y que no se debe amparar su enriquecimiento- no deberían impedir su reparación ${ }^{111}$. Esta solución implica atribuir a la responsabilidad civil en este ámbito -atendidas sus características- una finalidad que trasciende la estrictamente compensatoria ${ }^{112}$.

Otro punto central en materia de prueba del daño en esta esfera es el del mecanismo destinado a mensurarlo y, en definitiva, a saber cuánto 116 pagar a cada grupo o subgrupo de consumidores por los perjuicios experimentados por la colusión. El tribunal, a la luz de los informes periciales allegados al juicio, deberá avaluar los menoscabos padecidos por los distintos grupos y subgrupos de consumidores conforme al mecanismo planteado más idóneo para el caso, sin perjuicio de que, si le parece razonable, pueda mezclar diversos métodos ${ }^{113}$. Dependiendo de la complejidad

${ }^{109}$ BüYÜKSAGIS (2015), pp. 22-23. Otras interesantes normas de la directiva son los arts. 5 y 6 , que contemplan la posibilidad de que los perjudicados soliciten a los demandados y la autoridad de la competencia, respectivamente, la exhibición de pruebas. Dunne (2015), pp. 585-587.

${ }^{110} \mathrm{El}$ art. 51.2 de la LPDC establece que en la demanda colectiva "bastará señalar el daño sufrido y solicitar la indemnización que el juez determine, conforme al mérito del proceso, la que deberá ser la misma para todos los consumidores que se encuentren en igual situación". AguirRezábal (2013a), p. 1025.

${ }^{111}$ Besomi (2014), pp. 123-124; Lewin (2011), p. 51; Banfi (2013), p. 241.

${ }^{112}$ Araya (2005), p. 19.

${ }^{113}$ Lewin (2011), p. 53; BANFi (2013), p. 240; Besomi (2014), p. 127. En este sentido y por lo que concierne al daño extrapatrimonial, cabe tener en cuenta que en virtud de la aprobación por el Congreso Nacional del proyecto de ley que modifica la LPDC, el nuevo inciso cuarto del art. 51.2 dispondrá: "en la determinación del daño moral sufrido por los consumidores, el juez podrá establecer un monto mínimo común, para lo cual, de oficio o a petición de parte, podrá ordenar un peritaje, sin perjuicio de poder considerarse otros medios de prueba". 
económica y jurídica del asunto, los mecanismos a utilizar podrán basarse en estadísticas y antecedentes de la realidad (modelo comparativo econométrico -diacrónico o con antecedentes de otros mercados-) o apoyarse mayormente en consideraciones teóricas ${ }^{114}$.

Por último, debe tenerse en cuenta que la responsabilidad civil de los infractores es solidaria, en aplicación del art. 2317 del código del ramo ${ }^{115}$.

\section{e) Causalidad}

Un siguiente problema atinente al daño es el de la relación causal que debe ligarlo con el ilícito de colusión. En este sentido, cabe recordar que solo se indemnizan los detrimentos conectados vía causalidad directa, fáctica y normativamente, con el ilícito ${ }^{116}$. Así, en el juicio indemnizatorio, se deberá acreditar que los respectivos perjuicios han surgido de manera inmediata, en sentido fáctico y normativo, de la colusión ${ }^{117}$.

Si bien la prueba de la causalidad, tratándose del daño representado por el sobreprecio pagado por los consumidores que contrataron con el infractor, puede no presentar inconvenientes significativos, sí los presentará tratándose de otros grupos o subgrupos de consumidores. Así, respecto de los que no contrataron con el infractor (sino con un individuo situado debajo de él) ${ }^{118}$; de los que, a consecuencia del sobreprecio, se vieron impedidos de acceder al respectivo bien o adquirieron uno de inferior calidad ${ }^{119}$; y de los que experimentaron detrimentos distintos del sobreprecio. Como sea, pese a las dificultades probatorias, acreditados los detrimentos de los consumidores, según los diversos grupos y subgrupos formados por el tribunal, deberán ser indemnizados, tanto los de quienes hayan comparecido al juicio como los de quienes, por cumplirse los requisitos legales a su respecto, resulten beneficiados por el efecto absoluto de la sentencia. Entre los medios de prueba destinados a este efecto se encuentran los de carácter directo, pero también las presunciones, atendida, principalmente, la asimetría informativa que afecta a los consumidores ${ }^{120}$.

${ }^{114}$ Comisión Europea (2013), p. 16 y ss.; Beaton-Wells (2016), pp. 729-735; Besomi (2014), p. 124 y ss.; LewIN (2011), p. 53 y ss.

${ }^{115} \mathrm{El}$ art. 11 de la directiva 2014/104/UE lo establece expresamente, precisando, eso sí, que en las relaciones internas de los infractores la responsabilidad es simplemente conjunta. Dunne (2015), p. 591.

${ }^{116}$ Barros (2006), pp. 246 y 383 y ss.

${ }^{117}$ Dunne (2015), p. 587; Waelbroeck, Slater y Even-Shoshan (2004), p. 110; BeatonWeLls (2016), pp. 723-725.

${ }^{118}$ Cengiz (2010), p. 54.

${ }^{119}$ Lewin (2011), pp. 49-50.

${ }^{120}$ Besomi (2014), pp. 61-62, 107-111 y 143-144. 


\section{Conclusiones}

1. Los casos de colusión conocidos en los últimos años han evidenciado en nuestro medio la conexión entre los derechos de la competencia y del consumo, que buscan mejorar el funcionamiento del mercado y la protección de los consumidores.

2. Tradicionalmente, el Derecho de la Competencia ha buscado prevenir, disuadir y castigar los ilícitos contra el mercado mediante herramientas del Derecho Público, pero es cada vez más frecuente que sean complementadas con mecanismos del Derecho Privado, como la responsabilidad civil a favor de los consumidores afectados por la colusión.

3. El art. 30 del DL 211 recoge la apuntada tendencia, dándose a los perjudicados por la colusión la posibilidad de deducir la acción indemnizatoria por los daños que hayan padecido.

4. En virtud de la reforma introducida al DL 211 y la LPDC por la ley $\mathrm{N}^{\circ} 20.945$, dicha tendencia se ha reforzado respecto de los consumidores al dárseles expresamente la posibilidad de deducir la acción indemnizatoria por los daños causados por un ilícito anticompetitivo, como la colusión.

5. Si bien a la luz del anterior art. 30 del DL 211 quedaba claro que los consumidores perjudicados por la colusión podían deducir una acción resarcitoria individual, se discutió acerca de si podían interponer una colectiva. En virtud de la reforma introducida al DL 211 y la LPDC por la ley No 20.945 la duda quedó zanjada, de manera que hoy los consumidores se encuentran habilitados para iniciar un procedimiento colectivo al efecto de ser compensados por los detrimentos provenientes de la colusión.

6. Entre los interrogantes que, en sede de acciones colectivas, plantea la responsabilidad civil derivada de la colusión, destacan los relativos a la legitimación activa y sus presupuestos, la culpabilidad y el daño.

7. Una de las preguntas atinentes a los presupuestos de la legitimación colectiva de los consumidores en este terreno es la de si al efecto de que puedan deducir la acción indemnizatoria por los daños causados por la colusión deben haber contratado con el infractor. En los casos en que lo hayan hecho, estarán habilitados para accionar, presentándose la duda cuando no lo hayan hecho, atendido que la LPDC exige, respecto de las acciones para proteger el interés colectivo (no el difuso), la concurrencia de un vínculo contractual.

En mi parecer, la LPDC no debería requerir la comprobación de un vínculo contractual para deducir acciones colectivas indem- 
nizatorias tratándose de ilícitos contra el mercado, debiendo procederse a su modificación al efecto de conceder legitimación para que puedan interponerlas, también, los consumidores que, pese a no haber contratado con proveedores coludidos, hayan concluido un contrato con uno que, a su vez, lo haya hecho con alguno de los concertados o con otro proveedor (productor, fabricante o distribuidor) de la cadena en que se produjo la colusión (como en el "Caso pollos"). Naturalmente, de reformarse en este sentido la LPDC, los consumidores, para ser resarcidos, deberían comprobar que su proveedor les repercutió todo o parte del sobreprecio que a su turno pagó a raíz de la colusión.

El apuntado planteamiento, me parece, es coherente con la concepción asumida por la LPDC en materia de ámbito objetivo de aplicación al gobernar relaciones no solo contractuales sino, también, no contractuales y, por consecuencia, en materia de ámbito subjetivo de aplicación, al definir las nociones de proveedores y consumidores sin basarse, por lo menos categóricamente, en la necesidad de que se haya celebrado un contrato.

8. Otro aspecto relevante en relación con los presupuestos de la legitimación de los consumidores en este terreno es el de la incidencia en el proceso resarcitorio de la sentencia sobre libre competencia del TDLC.

Dicha sentencia, en general, será necesaria al efecto de iniciar el juicio de responsabilidad civil ante el mismo tribunal, en el cual producirá efecto de cosa juzgada respecto de los hechos, debiendo comprobarse solo el daño y la causalidad (no la culpabilidad).

En mi opinión, pese a no contar con una sentencia de libre competencia, los consumidores podrían deducir la acción resarcitoria en el tribunal competente, ante el cual deberán probar todos los requisitos de la responsabilidad civil, incluida la conducta ilícita. Supuestos en que podría aplicarse esta posibilidad serían aquellos en que la autoridad decida no perseguir el ilícito de colusión ante el TDLC o no continuar haciéndolo (v.gr., por considerar prescrita la acción o haber celebrado con el infractor un acuerdo con carácter de equivalente jurisdiccional).

9. En cuanto a la culpabilidad, no debería exigirse su acreditación en el juicio de responsabilidad civil seguido con posterioridad a la sentencia de libre competencia del TDLC, porque en esta habrá de quedar constancia de dicha culpabilidad y porque produce efecto de cosa juzgada en el proceso resarcitorio. De exigirse su acreditación, los consumidores podrían beneficiarse de las presunciones de culpabilidad del Código Civil (por el hecho propio y el ajeno), 
de la figura de la culpa en la organización y de la presunción a que conduce la culpa infraccional presente en los lícitos contra el mercado, como la colusión.

10. En relación con el daño, debe comprobarse en el proceso de responsabilidad civil su existencia, naturaleza, monto y relación causal directa con la colusión.

En orden a la determinación de la existencia, naturaleza, monto y relación causal del daño provocado por la colusión, el tribunal deberá formar grupos y subgrupos de perjudicados. Así, deberá diferenciar entre los consumidores que contrataron con el infractor, los que no contrataron con él sino con otro agente de la cadena en que materializó la colusión y los que no pudieron adquirir bienes a consecuencia de ella. A su vez, dentro de los segundos, deberá distinguir entre los que adquirieron el producto con sobreprecio en virtud del "efecto paraguas" y los que adquirieron bienes de inferior calidad o en menor número del requerido.

La sentencia que declare la responsabilidad del demandado operará con efecto absoluto, pudiendo todos los consumidores perjudicados reclamar las correspondientes indemnizaciones, incluso los que no hayan participado en el proceso. Estos, aun cuando no hayan rendido prueba de sus menoscabos, podrán beneficiarse de la comprobación judicial de daños estandarizados para cada grupo y subgrupo de consumidores llevada a cabo por quienes hayan concurrido al proceso, siempre que a su respecto se cumplan los requisitos establecidos por la LPDC.

En general, la existencia, naturaleza, cuantía y causa del daño podrán acreditarla los consumidores mediante prueba directa o vía presunciones, sobre todo considerando que puede asumirse que la colusión siempre genera menoscabos.

Por lo que concierne a la naturaleza del detrimento, deberá resarcirse el patrimonial en su faceta de daño emergente (sobreprecio) y, en su caso, el lucro cesante (pérdida de rendimientos económicos por el pago de un sobreprecio). En cuanto al daño extrapatrimonial (v.gr., el padecido por los consumidores que, producto de la colusión, no contrataron o adquirieron bienes en menor cantidad o de inferior calidad a la requerida), la LPDC establece actualmente que no se indemniza si la acción deducida es colectiva. No obstante, en virtud de la reciente aprobación por el Congreso Nacional del proyecto de ley que modifica la LPDC, su nuevo art. 51.2 dispondrá, respecto del procedimiento colectivo, que dicho daño se indemniza, "siempre que se haya afectado la integridad física o síquica o la dignidad de los consumidores". 


\section{BIBLIOGRAFÍA CITADA}

Aguirrezábal, Maite (2013a). "Artículo 51", en Íñigo de la MaZa y Carlos PizaRRO (dirs.) y Francisca BARRIENTOS (coord.). La protección de los derechos de los consumidores. Comentarios a la Ley de Protección a los Derechos de los Consumidores. Santiago: Legal Publishing.

Aguirrezábal, Maite (2013b). "Artículo 54",en Î̃̃igo de la Maza y Carlos PizaRRO (dirs.) y Francisca BARRIENTOS (coord.). La protección de los derechos de los consumidores. Comentarios a la Ley de Protección a los Derechos de los Consumidores. Santiago: Legal Publishing.

Alison, Jones y Brenda Sufrin (2016). EU Competition Law: Text, Cases, and Materials. Oxford: Oxford University.

ArAYA, Fernando (2005): "Daño anticompetitivo y daño indemnizable: un ensayo de confrontación". Revista Chilena de Derecho Privado. No 4. Santiago.

Abeliuk, René (2014). Las obligaciones. Santiago: Legal Publishing. Tomo I.

BAnfi, Cristián (2014). "Acerca de la imputación de responsabilidad civil por ilícitos anticompetitivos entre rivales en Chile". Revista Chilena de Derecho. Vol. 41. No 1. Santiago.

BANFI, Cristián (2013). "La responsabilidad civil como forma de aplicación privada del derecho de la competencia". Revista Chilena de Derecho Privado. No 21. Santiago.

Barrientos, Francisca (2014). "Una vez más la responsabilidad infraccional y civil por sustracción de especies en los estacionamientos de un mall". Revista Chilena de Derecho Privado. No 22. Santiago.

Barrientos, Francisca (2010). "La responsabilidad civil del fabricante bajo el artículo 23 de la Ley de Protección de los Derechos de los Consumidores y su relación con la responsabilidad civil del vendedor". Revista Chilena de Derecho Privado. $\mathrm{N}^{\mathrm{O}}$ 14. Santiago.

Barros, Enrique (2006). Tratado de responsabilidad extracontractual. Santiago: Editorial Jurídica de Chile.

Beaton-Wells, Caron (2016). "Private Enforcement of Competition Law in Australia-Inching Forwards?”. Melbourne University Law Review. Vol. 39. № 3. Melbourne.

Berenguer, Luis (2011). "La aplicación privada del derecho de la competencia", en Luis Velasco et al. (dirs.), La aplicación privada del derecho de la competencia. Valladolid: Lex Nova.

BESOMI, María (2014). Indemnización a consumidores por ilícitos anticompetitivos: un análisis desde la perspectiva de la responsabilidad civil. Memoria para optar al grado de Licenciado en Ciencias Jurídicas y Sociales. Santiago: Universidad de Chile.

Bucan, Nina (2014). The Enforcement of EU Competition Rules by Civil Law. Antwerpen: Maklu. 
BüYÜKSAGIS, Erdem (2015). "Standing and Passing-on in the New EU Directive on Antitrust Damages Actions". Swiss Review of Business Law. Vol. 87. No 1. Zurich.

Carpagnano, Michele (2007). "El private enforcement del derecho comunitario de la competencia en acción: Análisis crítico de la decisión del Tribunal de Justicia en los asuntos acumulados C 295-298/04". Indret. No 1. Barcelona.

Cavanagh, Edward (2010). "The Private Antitrust Remedy: Lessons from the American Experience”. Loyola University Chicago Law Journal. Vol. 41. No 3. Chicago.

Cengiz, Firat (2010): “Antitrust Damages Actions: Lessons From American Indirect Purchasers' Litigation". International and Comparative Law Quarterly. Vol. 59. $\mathrm{N}^{\mathrm{O}}$ 1. Cambridge.

Comisión Europea (2013). Guía práctica cuantificar el perjuicio en las demandas por daños y perjuicios por incumplimiento de los artículos 101 o 102 del Tratado de Funcionamiento de la Unión Europea. Bruselas: Comisión Europea.

Comisión Europea (2008). Libro Blanco. Acciones de daños y perjuicios por incumplimiento de las normas comunitarias de defensa de la competencia, COM (2008) 165 final. Bruselas: Comisión Europea.

Contardo, Juan (2013). "Artículo $3^{\circ} \mathrm{E}$ ). Derecho a la reparación e indemnización”, en Íñigo DE LA MAZA y Carlos PIZARro (dirs.) y Francisca BARRIEnTOS (coord.). La protección de los derechos de los consumidores. Comentarios a la Ley de Protección a los Derechos de los Consumidores. Santiago: Legal Publishing.

122 CORRal, Hernán (2013). Lecciones de responsabilidad civil extracontractual. Santiago. Thomson Reuters.

Cortez, Gonzalo (2013). “Artículo 50”, en Íñigo de la Maza y Carlos Pizarro (dirs.) y Francisca BARRIEnTOS (coord.), La protección de los derechos de los consumidores. Comentarios a la Ley de Protección a los Derechos de los Consumidores. Santiago: Legal Publishing.

Diez, José (2012). El daño extracontractual. Santiago: Editorial Jurídica de Chile.

Domínguez, Carmen (2017). "Efectos de la sentencia dictada en sede de libre competencia en materia de responsabilidad civil: algunas notas en perspectiva evolutiva”, en Hernán Corral y Pablo Manterola (eds.), Estudios de Derecho Civil XII. Ponencias presentadas en las XIVJornadas Nacionales de Derecho Civil, 6 y 7 de octubre de 2016, Maitencillo. Santiago: Thomson Reuters.

Dunne, Niamh (2015). "Courage and Compromise: the Directive on Antitrust Damages". European Law Review. N 4 . London.

Eyzaguirre, Cristóbal y Jorge Grunberg (2008). “Colusión monopólica. Prueba de la colusión, paralelismo de conductas y factores añadidos". Revista Anales Derecho UC. $\mathrm{N}^{\mathrm{O}}$ 4. Santiago.

Fernández, Cani y Irene Moreno-Tapia (2002). "A step forward in the enforcement of community competition law by Member State judges: the Courage case". Indret. $\mathrm{N}^{\mathrm{O}} 1$. Barcelona.

FRÊNE, Guillermo (2011). "Análisis a la legitimación activa en el Decreto Ley 211". Revista Anales Derecho UC. N 6. Santiago. 
Fuch, Andrés y Álvaro Vives (2015). “Dos problemas en torno a la responsabilidad derivada de ilícitos anticompetitivos", en Álvaro Vidal, Gonzalo Severín, y Claudia Mejías (eds.), Estudios de Derecho Civil X. Jornadas Nacionales de Derecho Civil Valparaíso, 2014. Santiago: Thomson Reuters.

Geradin, Damien (2015). "Collective Redress for Antitrust Damages in the European Union: Is this a Reality Now?”. George Mason Law Review. Vol. 22, № 5 . Virginia.

Gómez, Sílvia (2011-2012). “Comentarios sobre algunas cuestiones contenidas en el Libro Blanco de acciones por daños por la infracción de las normas de competencia: la necesidad de armonización de la regulación del recurso colectivo y la protección a los partícipes en procedimientos de clemencia”. Actas de Derecho Industrial y Derecho de Autor. N ${ }^{\circ} 32$. Santiago de Compostela.

Guillén, Javier (2002). El estatuto jurídico del consumidor. Política comunitaria, bases constitucionales y actividad de la administración. Madrid: Civitas.

Hamilton, Andrea y David Henry (2012). "Bricks, Beer and Shoes: Indirect Purchaser Standing in the European Union and the United States". Global Competition Litigation Review. Vol. 5, No 3. London.

HernÁNDEZ, Gabriel (2017). "Indemnización a consumidores por los daños derivados de un ilícito anticompetitivo en el derecho chileno", en Hernán Corral y Pablo Manterola (eds.), Estudios de Derecho Civil XII. Ponencias presentadas en las XIVJornadas Nacionales de Derecho Civil, 6 y 7 de octubre de 2016, Maitencillo. Santiago: Thomson Reuters.

IoAnnidou, Maria (2015). Consumer Involvement in Private EU Competition Law Enforcement. Oxford: Oxford University.

ISLER, Erika (2014). "Comentario de sentencia sobre el concepto de consumidor". Revista Chilena de Derecho y Ciencia Política. Vol. 5. No 1 . Temuco.

Jones, Alison y Brenda Sufrin (2016). EU Competition Law: Text, Cases, and Materials. Oxfiord: Oxford University.

Komninos, Assimakis (2008). EC private antitrust enforcement: decentralised application of EC competition law by national courts. Oxford: Hart.

Kuijpers, Matthijs et al. (2015). "Actions for Damages in the Netherlands, the United Kingdom, and Germany". Journal of European Competition Law \& Practice. Vol. 6. No 2. Oxford.

LANDE, Robert (2011). "Beneficios potenciales de la aplicación privada del derecho de la competencia”, en Luis VELASCO et al. (dir.), La aplicación privada del derecho de la competencia. Valladolid: Lex Nova.

LeSKInEN, Charlotte (2011). "Reparaciones de daños y perjuicios en materia de defensa de la competencia: la conveniencia de las acciones colectivas opt-out en casos que implican numerosas demandas individuales de poco valor", en Luis VELASCO et al. (dis.), La aplicación privada del derecho de la competencia. Valladolid: Lex Nova.

LEwIN, Nicolás (2011). "Indemnización de perjuicios por atentados a la libre competencia: el daño anticompetitivo, su relación con el daño civil y la determinación de los perjuicios". Revista Anales Derecho UC. No 6. Santiago. 
Martínez de Aguirre, Carlos (1994). “Trascendencia del principio de protección a los consumidores en el Derecho de obligaciones". Anuario de Derecho Civil. Vol. 47. $\mathrm{N}^{\mathrm{O}}$ 1. Madrid.

Migani, Caterina (2014). "Directive 2014/104/EU: In Search of a Balance between the Protection of Leniency Corporate Statements and an Effective Private Competition Law Enforcement”. Global Antitrust Review. N ${ }^{\circ}$ 7. London.

Miranda, Luis (1999). “Competencia desleal y protección de los consumidores”, en Gema Botana y Miguel Ruiz (coords.), Curso sobre protección jurídica de los consumidores. Madrid: Mc Graw Hill.

Momberg, Rodrigo (2013). “Artículo $1^{\circ} \mathrm{N}^{0} 1$ ”, en Íñigo De la MAZA y Carlos PizArRo (dirs.) y Francisca BARRientos (coord.). La protección de los derechos de los consumidores. Comentarios a la Ley de Protección a los Derechos de los Consumidores. Santiago: Legal Publishing.

Ossa, Juan y Luis Álvarez (2013). "La etapa de admisibilidad de las acciones para la defensa del interés colectivo y difuso de los consumidores". Revista de Derecho · Escuela de Postgrado. Facultad de Derecho Universidad de Chile. No 4 . Santiago.

Salelles, José (2009). "La disciplina de los agentes económicos que operan en el mercado", en Rodrigo Bercovitz Rodríguez-Cano (dir.) y Nieves MoRAlejo y Susana Quicios (coords.), Tratado de contratos. Valencia: Tirant lo Blanch. Tomo I.

TAPIA, Javier (2010). "Acuerdos horizontales restrictivos de la competencia: una visión crítica aplicada al sistema chileno”, en Paulo MontT y Nicole NeHme, Libre competencia y retail. Un análisis crítico. Santiago: Legal Publishing.

TAPIA, Mauricio (2017). Protección de consumidores. Revisión crítica de su ámbito de aplicación. Santiago: Rubicón.

VALDÉs, Domingo (2009). Libre competencia y monopolio. Santiago: Editorial Jurídica de Chile.

VAn DEn Bergh, Roger (2013). "Private enforcement of european competition law and the persisting collective action problema". Maastricht Journal of European and Comparative Law. $\mathrm{N}^{\mathrm{O}} 1$. Maastricht.

Waelbroeck, Denis, Donald Slater y Gil Even-Shoshan (2004). Study on the Conditions of Claims for Damages in Case of Infringement of EC Competition Rules. Comparative Report. Brussels: Ashurst.

\section{Normas citadas}

\section{Código Civil.}

Código de Procedimiento Civil.

Decreto con fuerza de ley 1, Fija el texto refundido, coordinado y sistematizado del decreto ley $\mathrm{N}^{\circ}$ 211, de 1973. Diario Oficial, 7 de marzo de 2005.

Ley $N^{0}$ 19.496, Establece normas sobre protección de los derechos de los consumidores. Diario Oficial, 7 de marzo de 1997. 
Ley $\mathrm{N}^{\circ} 20.416$, fija normas especiales para las empresas de menor tamaño. Diario Oficial, 3 de febrero de 2010.

Ley $\mathrm{N}^{\circ} 20.945$, Perfecciona el sistema de defensa de la libre competencia. Diario Oficial, 30 de agosto de 2016.

\section{Jurisprudencia citada}

\section{Chilena}

Servicio Nacional del Consumidor con Farmacia Ahumada S.A. (2016): $1^{\mathrm{er}} \mathrm{Juz}-$ gado Civil de Santiago 10 de octubre de 2013 (acción por vulneración del interés colectivo), rol 37.607-2009; Corte de Apelaciones de Santiago 17 de noviembre de 2014 (recursos de casación en la forma y de apelación), rol 109-2014; Corte Suprema 7 de marzo de 2016 (recurso de casación en el fondo), rol 1.540-15. www.poderjudicial.cl

Requerimiento de la Fiscalía Nacional Económica contra Cencosud S.A. y otras (2016): Tribunal de Defensa de la Libre Competencia (requerimiento de la Fiscalía Nacional Económica por infracción del DL 211), rol 304-2016 (en tramitación). www.tdlc.cl

Servicio Nacional del Consumidor con SCA Chile S.A. (2016): Juzgado Civil de Colina (acción indemnizatoria por infracción de la ley $\left.N^{\circ} 19.496\right)$, rol 1.3742016 (en tramitación). www.poderjudicial.cl

Requerimiento de la FNE contra Agrícola Agrosuper S.A. y Otros (2015): Tribunal de Defensa de la Libre Competencia 25 de septiembre de 2014 (requerimiento de la Fiscalía Nacional Económica por infracción del DL 211), rol 236-2011, sentencia 139-2014; y Corte Suprema 29 de octubre de 2015 (recurso de reclamación), rol 27.181-2014. www.tdlc.cl

Requerimiento de la FNE contra CMPC Tissue S.A. y otra (2015): Tribunal de Defensa de la Libre Competencia (requerimiento de la Fiscalía Nacional Económica por infracción del DL 211), rol 299-2015 (en tramitación). www.tdlc.cl

Servicio Nacional del Consumidor con Agrícola Agrosuper S.A. y otros (2015): $29^{\circ}$ Juzgado Civil de Santiago (acción indemnizatoria por infracción de la ley $\mathrm{N}^{\mathrm{0}}$ 19.496), rol 28.470-2015 (en tramitación). www.poderjudicial.cl

Philip Morris Chile Comercializadora Limitada con Compañía Chilena de Tabacos S.A. (2013): $10^{\circ}$ Juzgado Civil de Santiago 25 de enero de 2010 (acción indemnizatoria por infracción del DL 211), rol 19.655-2009; Corte de Apelaciones de Santiago 8 de noviembre de 2011 (recursos de casación en la forma y de apelación), rol 1.520-2010; Corte Suprema 25 de julio de 2013 (recursos de casación en la forma y en el fondo), rol 1.339-2012. www. poderjudicial.cl

Servicio Nacional del Consumidor con Farmacias Cruz Verde S.A. y otros (2013): $10^{\circ} \mathrm{Juzgado}$ Civil de Santiago (acción indemnizatoria por infracción de la Ley $\mathrm{N}^{\mathrm{O}}$ 19.496), rol 1.940-2013 (en tramitación). www.poderjudicial.cl 
Requerimiento de la FNE contra Farmacias Ahumada S.A. y otros (2012): Tribunal de Defensa de la Libre Competencia 31 de enero de 2012 (requerimiento de la Fiscalía Nacional Económica por infracción del DL 211), rol 184-2008, sentencia 119-2012; y Corte Suprema 7 de septiembre de 2012 (recurso de reclamación), rol 2.578-2012. www.tdlc.cl

Sound Colour con United International Pictures Chile (2009): 10 Juzgado Civil de Santiago 30 de diciembre de 2005, rol 782-2004 (acción indemnizatoria por infracción del DL 211); Corte de Apelaciones de Santiago 30 de junio de 2009 (recurso de apelación), rol 1.361-2006. www.poderjudicial.cl

Producción Química y Electrónica Quimel S.A. con James Hardie Fibrocementos Ltda. (2009): 26 Juzgado Civil de Santiago 23 de junio de 2009 (acción indemnizatoria por infracción del DL 211), rol 2.191-2007. www.poderjudicial.cl

Cementa S.A. con James Hardie Fibrocementos Ltda. (2009): $26^{\mathrm{o}}$ Juzgado Civil de Santiago 24 de abril de 2009 (acción indemnizatoria por infracción del DL 211), rol 13.272-2007. www.poderjudicial.cl

Pivcevic y otros con Lan Chile (2006): $4^{\circ}$ Juzgado Civil de Santiago 22 de junio de 2000 (acción indemnizatoria por infracción del DL 211), rol 4.831-97; Corte de Apelaciones de Santiago 14 de julio de 2004 (recursos de casación en la forma y de apelación), rol 5.954-1999; y Corte Suprema 27 de diciembre de 2006 (recursos de casación en la forma y en el fondo), rol 5.835-2004. www. poderjudicial.cl

\section{Estadounidense}

California v. ARC America Corp (1989): 490 U.S. 93 (1989).

Illinois Brick v. Illinois (1977): 431 U.S. 720 (1977).

Hanover Shoe Inc. v. United Shoe Machinery Corp (1968): 392 U.S. 481 (1968).

\section{Europea}

Kone AG and Others v. ÖBB-Infrastruktur AG (2014): Tribunal de Justicia de la Unión Europea, 5 de junio de 2014, asunto C557/12.

Manfredi y Lloyd v. Adriatico Assicurazioni SpA (2006): Tribunal de Justicia de la Comunidad Europea, 13 de julio de 2006, asuntos acumulados C-295/04 a C-298/04.

Courage Ltd. v. Crehan (2001): Tribunal de Justicia de la Comunidad Europea, 20 de septiembre de 2001, asunto C-453-99.

Inglesa

Garden Cottage Foods Ltd. v. Milk Marketing Board: 1984, AC 130. 